Revista de Estudios Histórico-Jurídicos

[Sección historia del derecho europeo]

XXXVIII (Valparaíso, Chile, 2016)

[pp. 233 - 270]

\title{
La Historia: un lugar COMÚN PARA El Derecho CONTRACTUAL MARÍTIMO EUROPEO. CONCRECIÓN DE PRINCIPIOS RESPECTO AL FLETE*
}

[History: A Common Place for the European Maritime Contract Law. Fulfillment of Principles regarding Freight]

\author{
Patricia ZAMBrana MORAL** \\ Universidad de Málaga, España
}

\section{RESUMEN}

A partir de dos contratos marítimos básicos, como son el pasaje y el fletamento, tratamos de concretar algunos lugares comunes en su regulación en textos significativos para la historia del Derecho marítimo

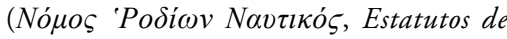
Marsella de 1253 a 1255, Rôles d'Oléron, Costums de Tortosa, Llibre del Consolat de Mar, Ordenanza de la Marina de 1681, Código de Comercio frances de 1807 o Código de Comercio español de 1885, entre otros). Pretendemos demostrar que en la historia se han mantenido determinados principios, centrándonos en el pago del flete como

\begin{abstract}
Based on the two main maritime contracts, namely, passage and charter, we attempt to reach some common places in their regulation in relevant texts of the

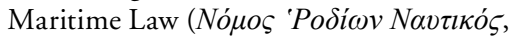
Statutes of Marseilles between 1253 and 1255, Rôles d'Oléron, Costums de Tortosa, Libre del Consolat de Mar, Great Ordinance of Marine of 1681, The French Commercial Code of 1807 or The Spanish Commercial Code of 1885 , among others). Our aim is to prove that certain principles have endured in history, focusing on the payment of the freight as the main obligation of the passen-
\end{abstract}

ReCibido el 13 de mayo y ACEPTADO el 9 de junio de 2016

* Trabajo realizado en el seno del Proyecto de Excelencia de la Junta de Andalucía: Derecho Europeo uniforme de contratos maritimos: Fundamentos históricos. Implicaciones medioambientales y económicas (P09-SEJ-4827) y, parcialmente, en el Proyecto INTELITERM: Sistema inteligente de gestión terminológica para traductores (FFI2012-38881, 2012-2015. MEC).

** Profesora titular de Historia del Derecho y de las Instituciones, Facultad de Derecho, Universidad de Málaga. Dirección: Boulevard Louis Pasteur, Campus de Teatinos, 29010 Málaga, España. E-mail: pzambrana@uma.es 
obligación principal del pasajero/mercader, lo que permitiría configurar un derecho común europeo en la materia si hubiese disponibilidad a nivel estatal.

\section{Palabras Clave}

Derecho marítimo - Derecho europeo - Fletamento - Flete - Contrato de pasaje marítimo - Contratos marítimos. ger/merchant, which allow to articulate a European common law in this matter if it was possible at a State level.

KEYwords
Maritime Law - European Law - Char-
ter - Freight - Maritime Passage Contract
- Maritime Contracts.
ter - Freight - Maritime Passage Contract - Maritime Contracts.

\section{INTRODUCCIÓN}

Partiendo de la indiscutible naturaleza histórica del Derecho marítimo en general y contractual en particular, que hemos tenido oportunidad de constatar en varias ocasiones, estamos en situación de afirmar que es en la Historia donde se localizan los principios básicos que han inspirado el Derecho contractual marítimo europeo hasta el punto de constituir un lugar común que podría servir de base para una legislación unificada que, tal vez, no vea la luz por motivos políticos más que jurídicos o históricos ${ }^{1}$. No es un posicionamiento nuevo ya que, históricamente, existió un derecho común marítimo que evolucionó a partir de los principales textos jurídicos y que se aplicó en Europa hasta que comienzan a surgir las leyes nacionales previas a la codificación, basadas en los mismos principios comunes (que se complementan con los tratados internacionales) contribuyendo a la aparición de "un moderno derecho común marítimo"2.

El planteamiento de diferentes opciones ante la construcción de un Derecho contractual europeo ${ }^{3}$ podría ser perfectamente extrapolable al Derecho contractual

1 Zambrana Moral, Patricia, Los fundamentos históricos y las implicaciones medioambientales y económicas de un Derecho europeo uniforme de contratos maritimos: una propuesta de investigación. Estado de la cuestión, en European Transport Law 46 (Antwerpen, 2011) 5, pp. 479-502; Un primer paso hacia un derecho europeo uniforme de contratos maritimos: el contrato de transporte de pasajeros por mar en el derecho histórico catalán, en European Transport Law 47 (Antwerpen, 2012) 6, pp. 583-621; La Ordenanza de la Marina francesa de 1681, un modo de entender el transporte de hombres libres al margen de la regulación legal, en REHJ. 37 (Valparaíso, 2015), pp. 175-207; Historia del contrato de pasaje marítimo. Derecho medieval e hipótesis de la aplicación analógica de la normativa fletamentaria. Unificación del Derecho europeo (Saarbrücken, OmniScriptum GmbH \& Co. KG, 2013); El transporte en la Ordenanza de la Marina francesa de 1681 (Cizur Menor, Aranzadi-Thomson Reuters, 2015). Sobre los motivos económicos, políticos o académicos de la unificación y la permeabilidad del sistema anglosajón, ver GARCÍA CARACUEL, Manuel, La alteración sobrevenida de las circunstancias contractuales (Madrid, Dykinson, 2014), pp. 384-385. En cuanto al estado de la cuestión sobre el Derecho contractual europeo, pp. 359385. Cfr. Pérez Velázquez, Juan Pablo, El proceso de modernización del Derecho Contractual Europeo (Madrid, Dykinson, 2013).

2 Tetley, William, Maritime Law as a Mixed Legal System (with Particular Reference to the Distinctive Nature of American Maritime Law, Which Benefits from Both Its Civil and Common Law Heritages, en Tulane Maritime Law Journal 23 (1999) 2, pp. 317-350, en pp. 321-322.

3 Se habla de no actuación, concreción de principios para lograr "convergencia de las leyes 
marítimo, pero la falta de avance en este campo nos hace dudar de las posibilidades de éxito de nuestra propuesta.

Centrándonos en dos tipos contractuales prototípicos, como son el pasaje marítimo y el fletamento, trataremos de concretar algunos de los lugares comunes en su regulación en textos significativos para la historia del Derecho marítimo que hemos analizado, permitiéndonos alcanzar conclusiones, y cuya riqueza no ha hecho necesario extender la selección para llegar a las mismas. Pretendemos demostrar que en la historia se han mantenido determinados principios, de los que recogemos solo una muestra en relación al pago del flete como obligación principal del pasajero/mercader en ambos $\operatorname{contratos}^{4}$, que deja abierta la puerta a un derecho común europeo si hubiese voluntad y sobre todo acuerdo, al respecto, a nivel estatal. Lo prueba la presencia de gran parte de los mismos, con algunos matices, en el derecho codificado francés (Código de Comercio de 1807 que reproduce, como veremos, en gran parte, la Ordenanza de la Marina de 1681) y español (del que nos centramos en el Código de Comercio de 1885) y sobre todo en uno de los textos más recientes sobre la materia, la vigente Ley 14/2014, de 24 de julio, de Navegación Marítima que será nuestro último referente y que, por otra parte, no hace sino confirmar la tendencia de los Estados europeos, empezando por el español, de legislar, a nivel nacional, sobre el Derecho contractual marítimo ${ }^{5}$, a pesar de que la evidente inspiración en principios históricos, algunos medievales, y su reiteración en textos posteriores hubiera permitido configurar un cuerpo legislativo único a nivel europeo.

\section{EL PAGO DEL PRECIO/FLETE COMO PRINCIPAL OBLIGACIÓN DEL PASAJERO/MERCADER-FLETADOR EN LOS CONTRATOS de pasaje marítimo y Fletamento. Primacía de la VOLUNTAD CONTRACTUAL}

Los elementos personales en el contrato de pasaje marítimo son el pasajero y el transportista, término genérico para referir a la otra parte contractual o persona obligada a llevar a cabo el transporte; mientras que en el contrato de fletamento podemos hablar de mercader/fletador/cargador, por un lado, y transportista por otro, apareciendo este último en la legislación histórica designado como patrón, señor de la nave, naviero, maestre, capitán o porteador, entre otras denominacio-

nacionales", “mejorar la calidad de la legislación en vigor” o "adopción de una legislación exhaustiva a nivel comunitario" [CAMPUZANO DíaZ, Beatriz, ¿Hacia un Derecho contractual europeo?, en Anuario de Derecho Europeo, 2 (2002), pp. 43-65]. Cfr. LA Misma, El plan de acción para un Derecho contractual europeo más coherente, en Anuario Mexicano de Derecho Internacional 4 (2004), pp. 289-309.

${ }^{4}$ Nos centramos en la obligación de pago, dejando a un lado otros aspectos que podrían estar relacionados con el flete como los derechos incluidos en el mismo o su contribución en caso de echazón.

${ }^{5}$ Lo mismo sucede en Francia donde se promulgó en 2010 el Code des transports que reúne toda la normativa sobre la materia de los transportes, incluido el marítimo, aunque, por razones de espacio no analizamos este texto sino que hemos optado por la Ley española de 2014 por ser más reciente. 
nes. Será básicamente la terminología que utilizaremos, sin mayores precisiones por escapar a nuestros objetivos en el presente trabajo. Efectuamos un análisis paralelo de ambos tipos contractuales en cuanto a aspectos básicos relacionados con el flete, partiendo de la posible aplicación de las reglas del fletamento al pasaje en supuestos de lagunas normativas a partir de la analogía. En cualquier caso, el examen no pretende ser exhaustivo sino significativo para concretar cada principio.

Del mismo modo que en el contrato de fletamento la prestación básica del mercader es satisfacer el flete, en el contrato de pasaje marítimo, la principal obligación del pasajero es el pago del precio del pasaje que también denominamos flete (utilizando indistintamente ambos vocablos) siguiendo la tradición histórica ${ }^{6}$, ya que, aunque no entremos en la naturaleza jurídica ${ }^{7}$, en muchos textos se considera el pasaje como un tipo de fletamento ${ }^{8}$ No obstante, la autonomía adquirida por este contrato hará que la normativa actual hable de precio o de pasaje. La regulación de esta obligación como primer e indiscutible principio o su intuición a falta de la misma se mantiene como constante en el derecho histórico. Así, hay referencias en los textos más antiguos aunque se tratase, muchas veces, de una reglamentación marginal a otras realidades.

Al margen del ámbito europeo, en el Código o Leyes de Manú (Mânava Dharma Sâstra $)^{9}$, que algunos consideran el primer legislador, se contemplaba ya el precio del transporte de pasajeros en viajes o trayectos largos, determinando que debía establecerse en función del lugar por el que se navegaba y la época del año, si se trataba de navegación fluvial, mientras que en la marítima se exceptuaba expre-

${ }^{6}$ Indicaba Bonniel que autores clásicos, como Pothier y Valin (e incluso Pardessus), no distinguían entre pasajeros y mercancías y usaban el término nolis para referir el precio tanto del pasaje como del transporte de mercancías [Bonniel, Y., Le contrat de passage (thèse pour le doctorat, Université d'Aix-Marseille-Faculté de Droit d'Aix, Aix-en-Provence, Imprimerie Universitaire E. Fourcine, 1936), p. 12].

7 Zambrana Moral, Patricia, cit. (n. 1), pp. 36-46. Cfr. Bonniel, Y., cit. (n. 6), pp. 11-20.

${ }^{8}$ Garrigues, Joaquín, Curso de Derecho mercantil (Madrid, S. Aguirre, 1940), II, 2, p. 784.

${ }^{9}$ Hemos utilizado las ediciones de JONEs, William, Institutes of Hindu Law: or, the Ordinances of Menu, according to the gloss of Culluca; comprising the Indian system of duties, religious and civil (Calcutta, printed by order of the government, London, reprinted for J. Sewell, Cornhill \& J. Debrett, Piccadilly, 1796), primera traducción inglesa; así como la traducción francesa, Lois de Manou, comprenant les institutions religieuses et civiles des Indiens (traduites du sanscrit et accompagnées de notes par Loiseleur DeslongChamps, Auguste Louis Armand, Paris, Imp. de Crapelet, 1833) [esta edición se recoge en Les livres sacrés de l'Orient, comprenant Le Chou-King ou le livre par excellence; les Sse-Chou ou les quatre livres de Confucius et de ses disciples; les lois de Manou, premier législateur de l'Inde; le Koran de Mahomet (traduits ou revus et corrigés par Pauthier, Guillaume, Orléans, H. Herluison, 1875), pp. 331-460]. También manejamos la selección de versos de contenido marítimo, con comentarios de Kullûka Bhatta, de PARDESsus, Jean Marie, Collection de lois maritimes antérieures au XVIII' siècle (Paris, L'Imprimerie Royale, 1845), VI, pp. 385-388 y las ediciones de STREhly, Georges, Mânava Dharma Çâstra. Les Lois de Manou (Paris, Ernest Leroux, 1893) y BüHLer, Georg, The Laws of Manu: The Sacred Books of the East Part Twenty-Five (edición de Müller, Friedrich Max, Oxford, Oxford University Press, 1885; reimpresión, Kessinger Publishing, 2004). 
samente esta regla ${ }^{10}$. A pesar de referirse al medio fluvial, vemos ya, en un texto ancestral, una regla aplicable en nuestros días: fijar el precio según la temporada ${ }^{11}$.

Podemos afirmar que un principio básico que se repite a lo largo de la historia es que la determinación del precio en los contratos que nos ocupan se hace depender de la autonomía de la voluntad de la partes reflejada en el documento contractual. Lo mismo sucederá en muchas otras cuestiones, actuando las normas en defecto de pacto en la mayoría de las ocasiones. Así, en el Mânava Dharma Sâstra no se precisaban de antemano los elementos a tener en cuenta para fijar el flete en el pasaje marítimo ${ }^{12}$, debiéndose acudir a lo pactado en el momento de concretar el viaje según sus características. No obstante, tanto en el transporte marítimo como en el terrestre se otorgaba fuerza de ley al precio fijado por hombres expertos en viajes, conociendo la zona, el tiempo y los objetos (a transportar), con independencia de que el contrato fuese por viaje o por tiempo ${ }^{13}$.

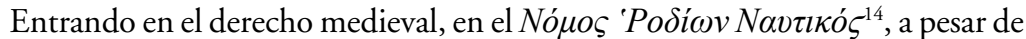
que hay muchas disposiciones relacionadas con el pasaje marítimo, a diferencia de otros textos históricos, no encontramos ninguna norma que regule la obligación principal del pasajero cuya delimitación se remitía a la voluntad contractual. Por

${ }^{10}$ Mânava Dharma Sâstra, VIII, sloka 406 [Jones, W., cit. (n. 9), p. 241; LoISEleur DESLONGCHAMPs, A., cit. (n. 9), VI, p. 387; BüHLer, G., cit. (n. 9), p. 253]. Para Pardessus, el sloka pretendía establecer legalmente el precio del transporte, quedando expresamente exceptuados los transportes por mar, a diferencia de la legislación "bouguie” que sí concretaba el flete en los viajes marítimos [cit. (n. 9), VI, p. 387, n. 1). El principal glosador de este Código, Kullûka Bhatta, cuyos comentarios son fundamentales para la interpretación del texto, reconducía el importe del flete al estado del agua que sería determinante para la dificultad de la navegación, lo que estaría directamente relacionado con la época del año en la que se realizaba el viaje que incidiría, a su vez, en una mayor o menor afluencia de pasajeros. Así, especifica que dependería del periodo de lluvias o de calor o de la estación (invierno o verano) en la que se desarrollase la travesía [PArdessus, J. M., cit. (n. 9), VI, p. 387; Strehly, G., cit. (n. 9), p. 253, en nota].

${ }^{11}$ Actualmente, hablaríamos de temporada alta o baja y probablemente la conclusión sería inversa en base a motivaciones económicas más que a la complejidad de la navegación: mayor precio en temporada alta y menor en temporada baja según el volumen de demanda, aspecto este prefijado por las agencias de viajes a la hora de contratar.

${ }^{12}$ Lo justificaba Kullûka en base a que el navío en el mar hacía depender su marcha del viento, siendo difícil su dirección, a diferencia de lo que sucedería en un río y esto impide establecer de antemano unas reglas de medida [PArdessus, J. M., cit. (n. 9), VI, p. 387].

${ }^{13}$ Mânava Dharma Sâstra, VIII, sloka 157 [JONES, W., cit. (n. 9), p. 210; LOISELEUr DESLONGChamps, A., cit. (n. 9), p. 274; PARdessus, J. M., cit. (n. 9), VI, p. 386; BÜHler, G., cit. (n. 9) p. 221]. Aunque la mayor parte de las ediciones manejadas referían en sus traducciones el transporte de mercancías, pensamos que no habría ningún inconveniente en hacer el sloka extensivo al transporte de pasajeros. No obstante, en otras ediciones, como la de W. Jones se interpretaba el precepto en relación al préstamo a la gruesa y a sus correspondientes intereses, opinión no compartida por Pardessus [Pardessus, J. M., cit. (n. 9), VI, p. 386, n. 2]. Cfr. BüHLER, G., cit. (n. 9), p. 282, en nota.

${ }^{14}$ La principal edición, sobre todo por sus comentarios, es la de AsHBURNER, Walter, Nó $\mu o \varsigma$

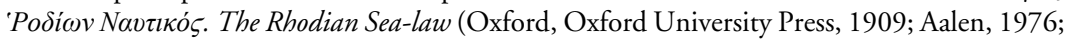
Union, Nueva Jersey, Lawbook Exchange, 2001). También hemos consultado la de PARDESSUs, Jean Marie, en Collection de lois maritimes antérieures au XVIII' siècle (Paris, L'Imprimerie Royale, 1828), I, pp. 231-260 y la de De Capmany y de Montpalau, Antonio, en Apéndice a las Costumbres Marítimas del Libro del Consulado (Madrid, Imprenta de Sancha, 1791), pp. 7-15. 
otro lado, aunque hay preceptos sobre el pago del flete por parte de los mercaderes, cuya aplicación analógica respecto al pasaje podría intuirse a falta de convenio, tampoco se dice nada sobre los criterios para su determinación ni sobre el momento en el que debía pagarse. Por tanto, la regla básica era que habría que atenerse a lo estipulado en el contrato respecto a su cuantía, tiempo y moneda de pago, ya que, como indica Ashburner, en general, el derecho estatutario medieval no solía recoger principios generales sobre este particular ${ }^{15}$ que sí se contenían en los documentos contractuales. Los Estatutos de Marsella de 1253 a $1255^{16}$ distinguían según el tipo de viaje para concretar la cuantía del flete y, en las travesías internacionales o de larga distancia, se permitía la intervención de la administración municipal ${ }^{17}$.

La primacía de la voluntad de las partes en los contratos marítimos aparece de forma expresa en las Partidas ${ }^{18}$ al señalar que todo pacto entre los "maestros" y los "señores de los navíos" con los mercaderes y "otros hombres que han de llevar en ellos" (pasajeros) es de obligado cumplimiento ${ }^{19} \mathrm{y}$, por tanto, también el relativo al precio, debiendo constar este, entre otras menciones, en la "carta de flete", imponiéndose una multa a cualquiera de las partes que incumpla el contrato $^{20}$. Del mismo modo, en los Rôles d'Oléron el contrato, en su forma de Charte-partie, era la regla a seguir ${ }^{21}$.

Sí que hay referencia expresa al precio del pasaje y a su obligación de pago

15 Sus reglas se dirigían a sancionar el incumplimiento de la obligación de pago del flete con un porcentaje de la cantidad debida; a establecer medidas para asegurar dicho pago (posibilidad de que el armador pudiera retener las mercancías en cantidad suficiente o exigir prenda al mercader) o a garantizar que una reclamación frente al armador en caso de pérdida o daños en los bienes no afectase a su derecho a cobrar el flete, dando seguridad al comerciante de que se acataría lo dispuesto por los tribunales [AsHBurner, Walter, cit. (n. 14), pp. CXCV-CXCVI)].

${ }^{16}$ Manejamos el extracto de los Estatutos de Marsella que reproduce PARDESSUs, Jean Marie, Collection de lois maritimes antérieures au XVIII siècle (Paris, L'Imprimerie Royale, 1837), IV, pp. 256-283. Cfr. Les Statuts municipaux et coutumes anciennes de la ville de Marseille (Marseille, 1656); PeRnOUd, Régine, Le IV $V^{\text {me }}$ Livre des statuts de Marseille (thèse complémentaire pour le Doctorat présentée à la Faculté des Lettres de l'Université de Paris, Marseille, A. GED, 1935); DE FRESQUet, Raimond Frédéric, Étude sur les statuts de Marseille au XIII siècle (Aix-Marseille, Makaire, 1865) y CRÉmieux, A., Le VIme livre des statuts de Marseille (Aix-en-Provence, F. Chauvet, 1917).

17 Statuta civitatis Massiliae, lib. IV, cap. XXIX, edición de Pardessus, Jean Marie, cit. (n. 16), IV, pp. 281-282. No podemos obviar que es el primer texto normativo en el que se regula el billete del pasaje indicándose que en el mismo debía constar el nombre y apellido del pasajero y el lugar que se le había asignado en la nave [Statuta civitatis Massiliae, lib. IV, cap. XXVI, edición de PARDEssus, Jean Marie, cit. (n. 16), IV, p. 279]. Se prohibía que los marineros exigiesen una cantidad adicional al pasajero por la emisión del billete, por sus literas o raciones de agua [Statuta civitatis Massiliae, lib. IV, cap. XXVIII, edición de PARDESsus, Jean Marie, cit. (n. 16), IV, p. 281].

${ }_{18}$ Hemos seguido la edición de las Partidas glosada por López, Gregorio (Salamanca, 1555).

19 Partidas, 5, 9, 2.

20 Partidas, 3, 18, 77.

${ }^{21}$ Rôles d'Oléron, XIII. Hemos empleado la edición de KRIEGER, Karl-Friedrich, Ursprung und Wurzeln der Rôles d'Oléron (Köln, Wien, Böhlau Verlag, 1970) y la de PARDEssus, Jean Marie, cit. (n. 14), I, pp. 323-353. 
en la definición que se ofrece del pasajero (peregrí) en las Costums de Tortosa $a^{22}$, al indicarse que era el que abonaba flete (nolit o loguer ${ }^{23}$ por su persona para que otro lo transportase en su leyn o en su nave o en su barca, al sitio donde se proponía llegar y viajaba sin mercancías. Por su parte, el mercader, fletador o cargador sería el que pagaba flete por sí mismo y por los géneros que tenía intención de trasladar al puerto de destino y, por tanto, se desplazaba con mercancías de su propiedad o de "su principal" si era dependiente o factor ${ }^{24}$. Sin embargo, las Costums no regulan la forma en que se debía pagar el precio del pasaje, aunque sí se contempla, de manera detallada, esta obligación en el transporte de mercancías, siendo muchas de las disposiciones, en las que luego nos detendremos, perfectamente extrapolables al pasaje. De nuevo, la regla inicial es someterse al contrato, siendo "la primera ley a la que hay que atenerse”, aplicándose lo establecido en las Costums si nada se hubiese pactado ${ }^{25}$.

El Llibre del Consolat de Mar (en adelante $L C M)^{26}$ también incluía el flete en el concepto de pasajero, distinguiendo con claridad el contrato de pasaje del fletamento: "tot home que deia donar nolit de la sua persona sens sa mercaderia" 27. El precio se abonaba por el transporte no solo de la persona sino también de sus

${ }^{22}$ Seguimos las ediciones de Oliver, Bienvenido, Historia del Derecho en Cataluña, Mallorca y Valencia. Código de las Costumbres de Tortosa (Madrid, Imprenta de Miguel Ginesta, 1881), IV y Massip i Fonollosa, Jesús, Costums de Tortosa (col-laboració de Duarte, C. y Massip, Á. y “pròleg” de FonT i Rius, J. M., Barcelona, Fundació Noguera, 1996).

23 Oliver lo traduce como "flete o alquiler" e indica que el nolit catalán tendría origen griego en un término que significaba alquiler de nave y se usaba en el derecho oriental y rodio, siendo adoptado por los latinos como naulum [OlIVER, Bienvenido, Historia del Derecho en Cataluña, Mallorca y Valencia. Código de las Costumbres de Tortosa (Madrid, Imprenta de Miguel Ginesta, 1879), III, p. 276, n. 1]. Cfr. Ashburner, Walter, cit. (n. 14), p. CXCIV y Ménager, Léon-Robert, "Naulum" et "Receptum rem salvam fore". Contribution à l'étude de la responsabilité contractuelle dans les transports maritimes, en droit romain”, en RHDFE. 38 (1960), pp. 177-213 y 385-411 y sobre el concepto de naulum, pp. 180-190.

${ }^{24}$ Costums de Tortosa, IX, 27, 3. Se trata de una norma fundamental en la que se contemplan los elementos y obligaciones de las partes en los contratos de fletamento y pasaje, entre ellas el pago del flete como prestación principal del mercader y del pasajero. En aquella época era costumbre que el mercader viajara con sus géneros, mientras que más tarde se entregaban al capitán para su transporte [OLIVER, Bienvenido, cit. (n. 23), III, p. 276].

${ }^{25}$ Costums de Tortosa, IX, 27, 28, párrafo 1. Ver Oliver, Bienvenido, cit. (n. 23), III, p. 291.

${ }^{26}$ Utilizamos varias ediciones del LCM: PARDESSus, Jean Marie, Collection de lois maritimes antérieures au XVIII siècle (Paris, L'Imprimerie Royale, 1831), II, pp. 49-368 (en francés y catalán, con comentarios, en pp. 1-48); Parellada, Juan Ramón, Libro del Consulado del Mar (Madrid, Ministerio de Asuntos Exteriores, 1955) y DE CaPMANy y de MontPalau, Antonio, Código de las Costumbres maritimas de Barcelona, hasta aquí vulgarmente llamado Libro del Consulado. Nuevamente traducido al castellano con el texto lemosin restituido a su original integridad y pureza; e ilustrado con varios apéndices, glosarios, y observaciones históricas (Madrid, Imprenta de Don Antonio de Sancha, 1791). Cfr. Colon i Domènech, Germà y Garcia i Sanz, Arcadi, Llibre del Consolat de Mar (Barcelona, Fundació Salvador Vives Casajuana y Fundació Noguera, 1981-1987), 4 volúmenes, (reedición, Fundació Noguera, 2001), 1 volumen y la edición francesa de Mayssoni, François, Le Consulat, contenant les Loix, Statuts, \& Coustumes touchant les Contracts, marchandises, \& negociation Maritime. Ensemble de la Navigation, tant entre Marchands, que Patrons de Navires, \& autres Mariniers (Aix-en Provence, Estienne David, 1635).

${ }^{27}$ LCM, cap. primer [46], edición de Pardessus, cit. (n. 26), II, p. 49. 
efectos personales. La diferencia entre las mercancías y el equipaje que marcaba, a su vez, la de mercader y pasajero, se situaba en el peso, siendo los quintales la unidad de referencia. Así, los bienes que pesaban menos de diez quintales tenían la consideración de equipaje y su portador sería un pasajero que pagaba flete por sí mismo y por sus pertenencias. Por el contrario, los géneros de más de diez quintales eran mercancías y su propietario un mercader que no pagaba flete por su persona sino por dichas mercancías. Otro criterio de distinción era la cuantía del flete (aunque lógicamente dependía del volumen de los géneros), de modo que no se consideraba mercader el que pagaba un flete inferior a diez besantes ${ }^{28}$.

Un texto trascendental para la historia del Derecho marítimo previo a la codificación fue la Ordenanza de la Marina francesa de $1681^{29}$, en la que se inspira el Código de Comercio de 1807 que analizamos de forma paralela ${ }^{30}$. En su Libro III se regulan los contratos marítimos prestando atención independiente al flete ("fret ou nolis") 31 , al contrato de fletamento ("chartes-parties, affrètements ou nolissements") y al conocimiento de embarque ${ }^{32}$. El contrato de fletamento se debía hacer por escrito ${ }^{33}$, exigiéndose una serie de menciones obligatorias entre las que se encontraba el flete con los posibles intereses de demora, dejando a la autonomía de la voluntad de las partes la posibilidad de incluir otras condiciones que considerasen convenientes, siempre que no fuesen contrarias a los usos y

${ }^{28}$ LCM, cap. CXIII, edición de Parellada, cit. (n. 26), p. 54; cap. CXII, edición de CAPMANY, cit. (n. 26), p. 189 y cap. LXVIII [113], edición de PARDESSUs, cit. (n. 26), II, p. 115.

${ }^{29}$ Consultamos la edición de Pardessus, Jean Marie, cit. (n. 16), IV, pp. 325-418; y los comentarios en Ordonnance de la marine, Du mois d'août 1681, Commentée \& Conférée avec les anciennes Ordonnances, le Droit Romain \& les nouveaux Réglemens (Paris, C. Osmont, 1714); así como los de Valin, René Josué, Nouveau Commentaire sur l'Ordonnance de la marine, Du Mois d'Août 1681. Où se trouve la Conférence des anciennes Ordonnances, des Us \& Coutumes de la Mer, tant du Royaume que des Pays étrangers, \& des nouveaux Réglemens concernans la Navigation \& le Commerce maritime. Avec des explications prises de l'esprit du texte, de l'Usage, des Décisions des Tribunaux \& des meilleurs Auteurs qui ont écrit sur la Jurisprudence nautique. Et des Notes historiques \& critiques, tirées la plupart de divers Recueils de Manuscrits conservés dans les dépôts publics (La Rochelle, Chez Jérôme Legier et Pierre. Mesnier, 1760), 2 volúmenes y POTHIER, Robert Joseph, Supplément au Traité du Contrat de Lonage, ou Traité des Contrats de Louage Maritimes (Paris, Chez les Frères Debure; Orléans, Chez la Veuve Rouzeau-Montaut, 1765) entre otros.

${ }^{30}$ Code de commerce, précédé des motifs. Présentés au Corps Législatif par M. Regnaud de Saint-Jean-d'Angely (Toulouse, Chez V. ${ }^{\text {ve }}$ Douladoure, 1807).

${ }^{31}$ Se trataba de "le loyer des vaisseaux, appellé fret ou nolis" (Ordonnance touchant la marine du Mois d'Août 1681, lib. III, tít. 3º, art. 1). Se aprecia la unificación de la tradición mediterránea y atlántica a partir de la indistinción terminológica. Así fret o nolis serían dos términos sinónimos para designar la cantidad que se debía pagar por el alquiler de una nave [Ordonnance de la marine, Du mois d'août 1681, cit. (n. 29), p. 198]. Valin lo define como el precio por el arrendamiento del buque o por el transporte de las mercancías [VALIN, René Josué, cit. (n. 29), I, p. 605].

32 En opinión de Lyon-Caen y Renault no es lógico que tanto la Ordenanza de la Marina como el Código de Comercio de 1807 regulen el fletamento en tres títulos diferentes ya que se trata de "tres partes de un mismo todo" [LYON-CAEN, Charles y RENAUlt, Louis, Traité de droit commercial (Paris, F. Pichon et Durand-Auzias, 1906-1916), 8 volúmenes, V, p. 486]. Lo mismo sostenía PARDESSUS, Jean Marie, cit. (n. 16), IV, p. 360, n. 7.

33 Ordonnance touchant la marine du Mois d'Aồt 1681, lib. III, tít. $1^{\circ}$, art. 1. 
costumbres, a la equidad natural y a las leyes ${ }^{34}$. Por tanto, el precio siempre debía constar en el contrato o en el conocimiento de embarque ${ }^{35}$ con independencia de la modalidad fletamentaria ${ }^{36}$. El pago del flete era la principal obligación del fletador una vez que los géneros llegaban a su destino ${ }^{37}$. El Código de Comercio francés de 1807 indicaba, expresamente, que el flete se regía por los acuerdos recogidos en el contrato o en el conocimiento de embarque ${ }^{38}$.

Siguiendo la tendencia histórica y prueba evidente del principio que estamos comentando, el Código de Comercio español de 1885 dejaba a la voluntad de las partes la fijación del precio del pasaje (que recogía como un tipo de fletamento) y si no se convenía, en manos del juez o tribunal, previa declaración de peritos ${ }^{39}$. Lo mismo podría decirse, en cuanto a la primacía de lo establecido en el contrato, del flete en el fletamento que debía constar en la correspondiente póliza ${ }^{40}$ y en el

${ }^{34}$ Ordonnance touchant la marine du Mois d'Août 1681, lib. III, tít. 1º, art. 3. Cfr. Code de commerce de 1807, art. 273, que no refiere la posibilidad de incluir otras menciones; PARDESSUS, Jean Marie, Cours de droit commercial ( $3^{a}$ edición, Paris, Chez Nève, Libraire de la Cour de Cassation, 1825), III, pp. 162 y 170; LyON-CAEn, Charles y Renault, Louis, cit. (n. 32), V, pp. 512-513; Pothier, Robert Joseph, cit. (n. 29), p. 17 y Valin, René Josué, cit. (n. 29), I, p. 589.

${ }_{35}$ Era otra de las menciones obligatorias del conocimiento de embarque como título probatorio de las mercancías cargadas en la nave y fundamental para exigir el pago del flete (Ordonnance touchant la marine du Mois d'Août 1681, lib. III, tít. 2º, art. 2). Ver Code de commerce de 1807, art. 281.

${ }^{36}$ Ordonnance touchant la marine du Mois d'Août 1681, lib. III, tít. 3o, art. 1. Se recogían distintos tipos de fletamento pero no era una lista cerrada sino que se admitía "en quelqu'autre manière que ce puisse estre" (Ordonnance touchant la marine du Mois d'Août 1681, lib. III, tít. $3^{\circ}$, art. 1, in fine). Cfr. Pardessus, Jean Marie, Cours, cit. (n. 34), III, pp. 159-162 y Pothier, Robert Joseph, cit. (n. 29), pp. 5-7. Según Valin, el más utilizado era el fletamento por toneladas o quintales. Para evitar que influyese en la concreción del flete, el capitán no tenía obligación de manifestar la capacidad del buque (aunque si lo hacía debía ajustarse a la verdad). En relación al transporte de mercancías de poco volumen, peso excesivo o elevado valor había que atenerse, en cuanto al precio, a lo pactado en el contrato que dependería del tiempo que se iba a invertir para su carga y descarga [VAlin, René Josué, cit. (n. 29), I, pp. 605-607].

${ }^{37}$ Aparte del flete, el patrón solía pactar, de forma expresa (de lo contrario no podía exigirla), el cobro de una cantidad complementaria no muy elevada por los servicios prestados, destinada, exclusivamente, a su beneficio sin tener que dar cuenta ni a los propietarios ni a la tripulación. Así lo indica Valin. Sin embargo, la doctrina no es pacífica. Boulay-Paty piensa que solo se podría admitir si los dueños y la tripulación hubiesen prestado consentimiento expreso ya que la regla general era que todos los beneficios del fletamento formasen parte de la masa común y fueran objeto del posterior reparto [BoulaY-PATY, Pierre Sébastien, Cours de droit commercial maritime, d'après les principes et suivant l'ordre du Code de commerce ( $9^{a}$ edición Bruxelles, Société belge de librairie, etc. Hauman \& Comp., 1838), I, p. 162]. Cuando esta prerrogativa (denominada en los textos antiguos le vin, le chapeau ou les chausses du maître) se sometía a la condición de que los mercaderes estuviesen satisfechos se podía negar demostrando lo contrario. Véase POTHIER, Robert Joseph, cit. (n. 29), pp. 8-10 y 54-88 y Valin, René Josué, cit. (n. 29), I, p. 589.

${ }_{38}$ Code de commerce de 1807, art. 286.

39 Código de Comercio de 1885, art. 693. La Exposición de Motivos precisa que se solía pagar por anticipado el precio del pasaje, de forma que las reglas previstas se observaban por las partes cuando no habían establecido otras.

${ }^{40}$ Código de Comercio de 1885, art. 652.8. Debía indicarse si se trataba de una cantidad alzada por un viaje, o un tanto al mes, o por la zona del buque que se iba a ocupar, o por el peso o medida de los géneros, "o de cualquier otro modo que se hubiere convenido". 
conocimiento de embarque ${ }^{41}$. La actual Ley 14/2014, de 24 de julio, de Navegación Marítima, que sí diferencia claramente entre fletamento y pasaje, recoge el pago del precio como obligación principal del pasajero ${ }^{42}$ (siendo mención imperativa del billete ${ }^{43}$ ) en el que está incluido el transporte de su equipaje "con los límites de peso y volumen fijados por el porteador o por los usos" ${ }^{4}$; pero tampoco establece criterios para su concreción ${ }^{45}$. Asimismo, deja expresamente fuera de su ámbito de aplicación el pasaje clandestino y el transporte amistoso, pero no el gratuito realizado "por un porteador marítimo de pasajeros" ${ }^{46}$. En cuanto al fletamento, la Exposición de Motivos declara el regimen legal derogable cuando haya una póliza. El abono del flete aparece como prestación principal a la hora de conceptuar el contrato ${ }^{47}$. El fletador es la persona obligada a pagar el flete en los téminos pactados, aunque se puede acordar que lo abone el destinatario de los bienes o el que contrató el transporte si aquel se niega, correspondiendo también a este último la parte impagada por el destinatario después de que el porteador ejercite los derechos de retención, depósito y venta previstos por la ley ${ }^{48}$. El porteador puede negarse a entregar los géneros al destinatario hasta que no le pague el flete y otras cantidades adeudadas cuando así conste en el conocimiento de embarque y cuando el destinatario sea el propio fletador aunque no se haya indicado nada ${ }^{49}$.

\section{Devengo del flete y forma de Pago. Posibilidad de abandonar los bienes. Derecho de Retención de LOS GÉNEROS PARA COBRAR EL FLETE}

En términos generales, el precio solo era exigible cuando el contrato se cumplía y el pasajero o las mercancías llegaban indemnes a su destino, no existiendo obligación de pago en caso contrario. Más adelante, veremos diferentes posibilidades en cuanto al incumplimiento, tanto por causa imputable a alguna de las partes como ajena a las mismas, y su repercusión en el flete. Sobre el momento en el que se devengaba el flete y debía hacerse efectivo y la forma de llevar a cabo el pago, cuando nada se había pactado, encontramos divergencias en los textos

${ }^{41}$ Código de Comercio de 1885, art. 706. El conocimiento de embarque era el único título para establecer los derechos y obligaciones de las partes a falta de póliza (Código de Comercio de 1885, art. 653) No obstante, el flete deja de ser mención obligatoria en el conocimiento de embarque en la Ley 14/2014, de 24 de julio, de Navegación Maritima, art. 248.

${ }^{42}$ Ley 14/2014, de 24 de julio, de Navegación Maritima, art. 293.1.

43 Ley 14/2014, de 24 de julio, de Navegación Maritima, art. 288.1.

44 Ley 14/2014, de 24 de julio, de Navegación Maritima, art. 294.

45 Ley 14/2014, de 24 de julio, de Navegación Maritima, art. 287.1.

46 Ley 14/2014, de 24 de julio, de Navegación Marítima, art. 287.2. Hay quien sostiene que si no hay precio no se puede hablar de contrato de pasaje sino de un "contrato atípico" al que se le aplicarían por analogía las disposiciones del contrato de pasaje, salvo en los aspectos relativos al precio [Olmedo Peralta, Eugenio, Régimen jurídico del transporte marítimo de pasajeros. Contratos de pasaje y crucero ("Prólogo", de Peinado Gracia, Juan Ignacio, Madrid-BarcelonaBuenos Aires-São Paolo, Marcial Pons, 2014), pp. 121-122].

${ }^{47}$ Ley 14/2014, de 24 de julio, de Navegación Maritima, art. 203.

48 Ley 14/2014, de 24 de julio, de Navegación Maritima, art. 235.

49 Ley 14/2014, de 24 de julio, de Navegación Maritima, art. 255. 
analizados. Salvo excepciones, suele ser una cuestión que, cuando se regulaba, dependía del tipo de fletamento.

Como dijimos, en la compilación rodia no había ninguna norma sobre cuándo debía pagarse el flete, ni en relación al pasaje ni al fletamento, lo que era común en gran parte del derecho estatutario medieval. Por el contrario, sí descubre Ashburner en los contratos distintas opciones sobre esta cuestión, reafirmándose el principio antes comentado de prioridad de la voluntad contractual. A veces, se abonaba una parte, que podía ser una simple señal, antes de que se iniciara la travesía marítima y el resto, al finalizar la misma; en otros casos, se pagaba por completo al comienzo del viaje y también cabía la posibilidad de que se abonase todo al final, aunque no era lo más común ${ }^{50}$.

Más precisa era la regulación de esta materia en las Costums de Tortosa, respecto al transporte de mercancías, aunque nada se diga en cuanto al de pasajeros, intuyéndose la aplicación por vía analógica de las disposiciones. Así, el flete se devengaba desde que comenzaba la carga y si el contrato era a quintarades existía la obligación de pagar el total pactado aunque finalmente no se cargasen todos los géneros $^{51}$. El precio se hacía efectivo en la moneda en curso en el puerto de destino, salvo que se hubiese convenido otra cosa. No obstante, si por circunstancias ajenas a las partes, era necesario efectuar la descarga en un lugar distinto, habría que atenerse a lo que pactasen al respecto ${ }^{52}$.

En el $L C M$ tampoco se recogía nada sobre las condiciones relativas al pago del precio del pasaje. No sucedía lo mismo con el transporte de mercancías donde, a pesar de que también imperaba el principio de primacía contractual, el flete se regulaba con detalle, siendo algunas normas aplicables al transporte de personas. En el fletamento a quintaladas, estando la nave aparejada y cargadas las mercancías y comenzando a navegar en el plazo acordado, se debían pagar los fletes "sin litigio alguno", pudiendo el patrón retener géneros cuyo valor fuese cuatro veces el precio que debía recibir para garantizar su pago ${ }^{53}$. El capitán debía atenerse al contrato en cuanto al abono del flete, aunque algún mercader ofreciera un precio superior, salvo que se añadiesen mercancías una vez completadas las quintaladas y no se hubiera acordado su importe ${ }^{54}$. Por su parte, el fletador debía también cumplir todo lo convenido con el patrón siempre que constase en escritura o se hubiera inscrito en el cartulario y, si había pactado el transporte a quintaladas

${ }^{50}$ Ashburner, Walter, cit. (n. 14), pp. CLXXXIX-CXCVII.

${ }^{51}$ Costums de Tortosa, IX, 27, 37. Se trataría de una de las posibilidades de incumplimiento contractual que luego veremos, analizando los supuestos en los que se devengaba el flete completo, una parte, o no se devengaba nada.

52 Costums de Tortosa, IX, 27, 44.

53 LCM, cap. LXXXIII, edición de Parellada, cit. (n. 26), p. 36 y cap. XXXVIII [83], edición de PARDESSUs, cit. (n. 26), II, pp. 82-83. Cfr. LCM, cap. LXXXVI, edición de PARELLADA, cit. (n. 26), p. 38 y cap. XLI [86], edición de PARdessus, cit. (n. 26), II, pp. 86-87.

${ }^{54} L C M$, cap. LXXXVIII, edición de PARELLADA, cit. (n. 26), p. 38 y cap. XLIII [88], edición de Pardessus, cit. (n. 26), II, pp. 87-88. Sobre la costumbre del patrón de pactar fletes bajos y la posibilidad de encontrar después ofertas superiores y las consecuencias de no efectuar el transporte de lo inicialmente convenido, ver $L C M$, cap. XC, edición de PARELLADA, cit. (n. 26), p. 43 y cap. XLV [90], edición de Pardessus, cit. (n. 26), II, pp. 95-96. 
pese a que no embarcase los géneros, pagaba el flete total estipulado ${ }^{55}$. Las partes tenían que acordar el precio por escrito o en presencia del escribano, ya que, de lo contrario, no tendría efectividad si una de ellas no reconocía el contrato ${ }^{56}$. Por otro lado, el mercader debía reembolsar los fletes de todas las mercancías que le entregaba el capitán en el lugar de destino, incluso de las que se habían mojado o dañado, aunque, previamente, el patrón tenía que prestar fianza ante las autoridades consulares para hacer frente a los daños o a los géneros que faltasen ${ }^{57}$.

La Ordenanza de la Marina de 1681 hacía depender el devengo del flete del tipo de fletamento. Si el buque se había fletado por mes, este se contaba desde el día en que zarpaba, salvo que se hubiese pactado lo contrario ${ }^{58}$ y, lógicamente, el patrón era el principal interesado en que no hubiese ningún retraso para poder $\operatorname{cobrar}^{59}$. Cuando fletaba la nave completa, el fletador tenía derecho a recibir el flete de los géneros que se embarcaban para completar la carga ${ }^{60}$, debiendo mantenerse el mismo precio $^{61}$.

55 LCM, cap. CII, edición de Parellada, cit. (n. 26), p. 49 y LVII [102], edición de Pardessus, cit. (n. 26), II, pp. 107-108. Sobre este particular insistimos al hablar del incumplimiento.

${ }^{56}$ LCM, cap. CCCXXX, edición de Parellada, cit. (n. 26), pp. 213-215.

${ }^{57} L C M$, cap. XXVII, edición de PARELLADA, cit. (n. 26), p. 10. El LCM regula el flete según el tipo de carga, prevaleciendo siempre la voluntad contractual. Por razones de espacio no entramos en su desarrollo. Así, se contempla el transporte de vino [ $L C M$, cap. CCV, edición de Parellada, cit. (n. 26), pp. 94-95 y cap. CLX (205), edición de Pardessus, cit. (n. 26), II, pp. 180-182], de tinajas [LCM, cap. CCXXXVII, edición de PARELLADA, cit. (n. 26), pp. 118-119y cap. CXCVII (237), edición de PARDESSus, cit. (n. 26), II, pp. 220-222 y LCM, cap. CCLXXIV, edición de ParelLada, cit. (n. 26), pp. 161-162 y cap. CCXXIX (274), edición de Pardessus, cit. (n. 26), II, pp. 299-300]; de grano [LCM, cap. CCLXIX, edición de PARelladA, cit. (n. 26), pp. 156-157 y cap. CCXXIV (269), edición de PARDESsus, cit. (n. 26), II, pp. 289-291] o de madera [LCM, cap. CCXCI, edición de Parellada, cit. (n. 26), p. 189 y cap. CCXLVI (291), edición de PARDESSus, cit. (n. 26), II, pp. 347-349].

${ }^{58}$ Ordonnance touchant la marine du Mois d'Aồt 1681, lib. III, tít. $1^{\circ}$, art. 5. Lo mismo se recoge en Code de commerce de 1807, art. 275. Según Pardessus la regla no tendría mucha aplicación en la práctica más moderna [PARDESSUs, Jean Marie, cit. (n. 16), IV, p. 359, n. 3 y Cours, cit. (n. 34), III, p. 160]. Lo que se establece es un cómputo para pagar el flete que se solía estipular en travesías de duración indeterminada por la lejanía del destino [FERNÁNDEZ-GUERRA FERnÁNDEZ, Ramón, El fletamento en las Ordenanzas del Consulado de Bilbao de 1737, en AHDE. 62 (1992), p. 128].

59 En base a la primacía de la voluntad de las partes, también se podía acordar que el flete se devengase aunque el buque no hubiera zarpado. En tal caso, los interesados en partir eran los mercaderes y el que ocasionaba el retraso tendría que indemnizar a los perjudicados. El fletamento por meses entraría en desuso (siendo sustituido por el de la totalidad de la nave o por quintales o toneladas) aunque era una modalidad que, en cierto modo, garantizaba que el capitán no extendiese la travesía para aumentar el precio [VALIN, René Josué, cit. (n. 29), I, p. 591].

${ }^{60}$ Ordonnance touchant la marine du Mois d'Août 1681, lib. III, tít. 3º, art. 28.

${ }^{61}$ Así se evitaba que un mercader pagase más que otro [VAlin, René Josué, cit. (n. 29), I, p. 640]. Para justificar el pago del precio era muy importante que el capitán tuviese en el buque un ejemplar del contrato de fletamento y cualquier otro documento que probase la carga (conocimiento de embarque, facturas, recibos...) (Ordonnance touchant la marine du Mois d'Aồt 1681, lib. III, tít. 1º, art. 10). Cfr. Valin, René Josué, cit. (n. 29), I, pp. 594-595; Pardessus, Jean Marie, cit. (n. 16), IV, p. 359, n. 8 y Cours, cit. (n. 34), III, pp. 62-63. Véase Code de commerce de 1807, art. 226. 
La Exposición de Motivos del Código de Comercio español de 1885 establecía que el flete solo se devengaba si el transporte se realizaba en los términos pactados y llegaban las mercancías al puerto de destino, aunque había algunas excepciones ${ }^{62}$. Se remitía el devengo a las condiciones fijadas en el contrato y si no había o eran dudosas se computaba desde el día en que se ponía el buque a la carga en el fletamento por meses o días; desde el mismo día, si era por tiempo determinado; y si se ajustaba por peso, se hacía el pago "por el peso bruto", incluyendo los envases y las barricas ${ }^{63}$. Una vez descargados los bienes y puestos a disposición del consignatario, este debía pagar al capitán el precio devengado ${ }^{64}$. Cualquier aumento natural en el peso o medida de los géneros iba en beneficio de su propietario, devengando el flete estipulado en el contrato ${ }^{65}$.

En la Ley de Navegación Marítima de 2014, el cálculo y devengo del flete se somete a lo pactado en el contrato y, en su defecto, si se calcula por el peso y volumen de los géneros hay que atenerse a lo que se declaró en el conocimiento de embarque, salvo fraude o error; y si se trata de un fletamento por tiempo, se devenga día a día, durante todo el tiempo que la nave esté “a disposición del fletador en condiciones que permitan su efectiva utilización por este" ${ }^{\text {"66. }}$.

Por otra parte, la posibilidad de abandono de la totalidad de los bienes cargados, con independencia de su valor, para satisfacer el flete, como principio, se admitía en las Costums de Tortosa ${ }^{67}$ y en el $L C M^{68}$. Según la Ordenanza de la Marina de 1681, los fletadores no podían obligar al patrón a recibir como flete los géneros en mal estado, con independencia de la causa, ni aquellos que se

${ }^{62}$ Una de las excepciones sería respecto a las mercancías vendidas durante el viaje por necesidades urgentes o para reparaciones imprescindibles que sí devengaban flete (Código de Comercio de 1885, art. 659).

63 Código de Comercio de 1885, art. 658.

${ }^{64}$ Código de Comercio de 1885, art. 686.

${ }^{65}$ Código de Comercio de 1885, art. 664.

${ }^{66}$ Ley 14/2014, de 24 de julio, de Navegación Marítima, art. 233. Vemos, de nuevo, como la regla del devengo se hace depender del tipo de fletamento si no hay pacto al respecto.

${ }^{67}$ Costums de Tortosa, IX, 27, 41. Así, cuando el dueño de las mercancías (mercader) y de "otras cosas" (pasajero) cargadas en la nave las "abandonaba" en su totalidad al naviero en concepto de flete, quedaba exento de su pago.

${ }^{68} \mathrm{El}$ patrón podía aceptar como pago una parte de los géneros, según su valor en el lugar de descarga, a propuesta de los mercaderes (sin que pudiesen obligarlo a ello) o por orden de la autoridad. También era posible que los fletadores dejasen la totalidad de la carga como pago de los fletes, no pudiendo, en tal caso, el capitán oponerse ni exigirles nada más [LCM, cap. CCLXX, edición de Parellada, cit. (n. 26), pp. 157-159; cap. CCLXIX, edición de CapmanY, cit. (n. 26), pp. 119-122 y cap. CCXXV (270), edición de PARDEssus, cit. (n. 26), II, pp. 291294]. Sin embargo, si la nave se fletó a tanto alzado con mercancías de diversa especie y las que se pretendían abandonar no alcanzaban a cubrir los fletes, el patrón no estaba obligado a aceptarlas. Cuando los mercaderes no podían vender los bienes se les permitía realizar un trueque con otros para pagar con estos, salvo que el capitán se negase, en cuyo caso seguían adeudando el flete íntegro pactado aunque necesitaran invertir todos los géneros. Pero el señor de la nave podía conceder un aplazamiento hasta que la venta fuese posible recibiendo, además, una parte proporcional de las ganancias si había [ $L C M$, cap. CCLXXV, edición de PARELLADA, cit. (n. 26), pp. 162-163; cap. CCLXXIV, edición de CAPMANY, cit. (n. 26), pp. 122-124 y cap. CCXXX (275), edición de Pardessus, cit. (n. 26), II, pp. 301-303]. 
habían depreciado ${ }^{69}$. En sentido similar, con algunos matices, se pronunciaba el Código de Comercio español de $1885^{70}$ y la Ley de Navegación Marítima de 2014, devengando las mercancías averiadas el correspondiente flete ${ }^{71}$.

En cuanto al derecho del transportista a retener los géneros cargados en la nave para garantizar el cobro de los fletes y cualquier otra cantidad que se le adeudase (perfectamente extensible al equipaje de los pasajeros) se contempla en la mayoría de los textos analizados. En los Rôles d'Oléron se limitaba a los casos en los que el buque sufría daños pero se salvaban algunos bienes y solo respecto al flete proporcional a la parte de la travesía realizada ${ }^{72}$.

Con carácter general, en las Costums de Tortosa estaba prevista la facultad del patrón de tomar "por su propia autoridad" y retener en prenda los objetos (mercancías y equipaje) embarcados, en la cantidad suficiente para cubrir el flete y las averías hasta que fuesen satisfechos al escribano, sin necesidad de que interviniese el veguer ni ninguna otra autoridad ${ }^{73}$.

También en el $L C M$ se reconocía el derecho del señor de la nave a retener los bienes y no descargarlos, en garantía del pago, hasta que los mercaderes le asegurasen el mismo, siempre que el buque llegase al puerto de destino y en el contrato no se hubiera fijado un día o plazo para pagar, ya que, en tal supuesto, no se podía impedir la descarga salvo sospecha de estafa por parte de los fletadores ${ }^{74}$.

${ }^{69}$ Ordonnance touchant la marine du Mois d'Aô̂t 1681, lib. III, tít. 3º, art. 25. Es un principio básico, que se reproduce en Code de commerce de 1807, art. 310. 1, ya que no era justo que el flete se viese afectado por motivos ajenos a la responsabilidad del patrón. No obstante, Valin considera que, aunque la Ordenanza no lo hace, habría que distinguir los daños que sufrían los géneros por causa fortuita de los que acontecían por vicio propio y reflexiona sobre situaciones excepcionales en las que el flete se podía rebajar en conexión con la regulación de la Ordenanza y con la opción de abandonar los bienes [VALIN, René Josué, cit. (n. 29), I, pp. 627 y 635-637]. Según el Code de commerce de 1807, art. 309, el cargador nunca podía pedir una disminución del flete. Ver Pardessus, Jean Marie, Cours, cit. (n. 34), III, pp. 182-183 y LyOn-CaEn, Charles y Renault, Louis, cit. (n. 32), V, pp. 610-611. Situación particular era la de los géneros que, por su naturaleza, se contenían en barricas o toneles (vino, aceite, miel y licores). Cuando se derramaban de modo fortuito, dejando los recipientes vacíos o casi vacíos, se podían entregar como pago, salvo que mediase culpa del capitán o de los marineros que estarían, en tal caso, obligados a reparar los perjuicios al mercader una vez deducido el flete (Ordonnance touchant la marine du Mois d'Août 1681, lib. III, tít. 3º, art. 26). Véase Code de commerce de 1807, art. 310. 2. Valin incluye el azúcar en la norma a pesar de no ser un líquido [VALin, René Josué, cit. (n. 29), I, p. 638]. Cfr. Pardessus, Jean Marie, cit. (n. 16), IV, p. 364, n. 2 y Cours, cit. (n. 34) III, pp. 182-183.

${ }^{70}$ Se dispone que no se podían abandonar las mercancías averiadas por vicio propio o caso fortuito para pagar el flete, salvo que se tratase de líquidos y se hubiesen derramado, quedando en los recipientes tan solo una cuarta parte (Código de Comercio de 1885, art. 687).

${ }^{71}$ Ley 14/2014, de 24 de julio, de Navegación Maritima, art. 234. 2.

72 Rôles d'Oléron, IV.

73 Costums de Tortosa, IX, 27, 17 y Costums de Tortosa, IV , 6, 9, párrafo 2. Como veremos, se exigía declarar al escribano y al naviero todos los bienes cargados, además de los resultantes del contrato, debiéndose flete por los mismos y, en caso contrario, si sufrían daños, el señor de la nave no era responsable, pudiendo retenerlos hasta que se pagase el precio más alto correspondiente a cualquier otro objeto en la travesía (Costums de Tortosa, IX, 27, 38).

${ }^{74}$ LCM, cap. CCLXX, edición de Parellada, cit. (n. 26), pp. 157-159; cap. CCLXIX, edición de CAPMANY, cit. (n. 26), pp. 119-122 y cap. CCXXV [270], edición de PARDEssus, cit. 
El escribano debía rendir cuentas de todo lo que recibía en concepto de flete y estaba, asimismo, facultado para tomar en prenda, tanto de los mercaderes como de los pasajeros o de cualquier persona que tuviese que satisfacer flete, lo que creyese oportuno para garantizar su abono ${ }^{75}$. El mismo derecho de retención se concedía al patrón en los Capitols del Rei en Pere ${ }^{76}$.

En la Ordenanza de la Marina de 1681 y en el Código de Comercio francés de 1807, el cumplimiento del contrato quedaba garantizado por la nave y sus aparejos, por el flete y por la carga ${ }^{77}$. Se imponía, como privilegio del capitán para el cobro del flete, el carácter preferente de los géneros que estaban en el buque, en los remolques o en el muelle, incluso quince días después de la entrega, siempre que no hubiesen pasado a manos de un tercero ${ }^{78}$. Sin embargo, la Ordenanza negaba al patrón el derecho a retener los bienes en la nave a falta de pago del flete y tan solo podía oponerse a su transporte en el momento de la descarga (lo que no deja de ser una especie de retención) o embargar las gabarras o los remolques ${ }^{79}$. Lo mismo se establece, con alguna modificación, en el Código de Comercio de $1807^{80}$. Se admitía que el capitán vendiese, con autorización judicial, las mercancías necesarias para cobrar el flete (depositando el resto) cuando la persona que, según el conocimiento de embarque, debía recibirlas se negaba a hacerlo ${ }^{81}$.

(n. 26), II, pp. 291-294. Si la nave se fletó a quintaladas y los mercaderes no hicieron solidarias las mercancías para pagar el precio, el patrón no podía retener unos géneros por otros $[L C M$, cap. CCLXXV, edición de Parellada, cit. (n. 26), pp. 162-163; cap. CCLXXIV, edición de Capmany, cit. (n. 26), pp. 122-124 y cap. CCXXX (275), edición de Pardessus, cit. (n. 26), II, pp. 301-303]. Como dijimos, en este tipo fletamentario había que atenerse a los plazos establecidos en el contrato para que el buque estuviese aparejado y comenzara a navegar y para que el mercader efectuase la carga y, en tal caso, se debía el flete, pudiendo el capitán retener bienes por valor de cuatro veces los fletes pactados [ $L C M$, cap. LXXXIII, edición de PARELLADA, cit. (n. 26), p. 36 y cap. XXXVIII (83), edición de PARDESSUS, cit. (n. 26), II, pp. 82-83].

${ }^{75}$ LCM, cap. LX, edición de Parellada, cit. (n. 26), p. 27 y cap. XV [60], edición de Pardessus, cit. (n. 26), II, pp. 68-69.

${ }^{76}$ Capitols del Rei en Pere, XXXIII. Se podía retener lo suficiente para cubrir no solo los fletes impagados, sino también la indemnización en caso de echazón.

77 Ordonnance touchant la marine du Mois d'Aô̂t 1681, lib. III, tít. 1º, art. 11 y Code de commerce de 1807, art. 280. Ver Pardessus, Jean Marie, cit. (n. 16), IV p. 360, n. 1 y Valin, René Josué, cit. (n. 29), I, pp. 595-596.

${ }_{78}$ Ordonnance touchant la marine du Mois d'Aô̂t 1681, lib. III, tít. 3o, art. 24 y Code de commerce de 1807, art. 307 (añade que el privilegio no se veía afectado por la quiebra del deudor). Cfr. Pothier, Robert Joseph, cit. (n. 29), pp. 85-87 y Valin, René Josué, cit. (n. 29), I, pp. 632-634.

79 Ordonnance touchant la marine du Mois d'Aô̂t 1681, lib. III, tít. 3º, art. 23. Casi siempre, los que recibían las mercancías comprobaban su estado antes de pagar por lo que no tenía sentido que el capitán cobrase antes de mostrar los géneros. De hecho, en la práctica, la norma no tendría mucha aplicación ya que, por costumbre, el maestre solía exigir el flete tras adjudicar los bienes y, en travesías largas, incluso tres meses después con el fin de que los géneros se vendiesen y se pagase con el importe de la venta [VALIN, René Josué, cit. (n. 29), I, pp. 631-632].

${ }^{80}$ Se negaba al capitán el derecho de retención, pero se permitía el depósito de los géneros en manos de un tercero hasta que se llevase a cabo el pago (Code de commerce de 1807, art. 306).

${ }^{81}$ Ordonnance touchant la marine du Mois d'Aồt 1681, lib. III, tít. 3o, art. 17 y Code de commerce de 1807, art. 305. Sería una "venta judicial de la carga por impago del flete" [FERNÁNDEZ-GUERRA FERNÁNDEZ, R., cit. (n. 58), p. 121]. Los géneros podían ser inspeccionados por 
Siguiendo estos principios, el Código de Comercio español de 1885 disponía que el cargamento estaba afecto al pago del flete y otros gastos, pero no se permitía al patrón dilatar la descarga por temor a que no se cumpliera la obligación de pago; aunque, en caso de desconfianza, podía pedir que el juez decretase el depósito $^{82}$. La carga se encontraba obligada "preferentemente a la responsabilidad de sus fletes y gastos durante veinte días", desde la entrega o depósito, pudiendo solicitarse la venta en este plazo (para el abono del flete, gastos y averías) salvo que hubiese pasado a un tercero de buena fe y a título oneroso ${ }^{83}$. En sentido similar se regula esta cuestión en la Ley de Navegación Marítima de 2014 aunque el plazo se reduce a quince días ${ }^{84}$. De otro lado, el Código de Comercio de 1885 facultaba al capitán, si no se encontraba al consignatario o se negaba a recibir los géneros, a requerir del juez el depósito y venta de lo necesario para cobrar los fletes ${ }^{85}$. Por su parte, la Ley de Navegación Maritima reconoce el derecho del porteador tanto a retener los bienes transportados mientras no perciba el flete y otras cantidades que se le adeuden como a "acudir al expediente de depósito y venta de mercancías o equipajes”, solicitando a un notario dicha venta, siempre que el destinatario sea el fletador, salvo que en el conocimiento se indique que el flete se paga en el destino ${ }^{86}$. En el fletamento por tiempo también puede el porteador "retener o depositar las mercancías por impago de fletes" cuando sean propiedad del fletador y si pertenecen a un tercero, la retención o el depósito solo se admite "por el importe de los fletes" que aquel deba todavía al fletador ${ }^{87}$. Por tanto, esta ley adopta el tradicional principio histórico del derecho de retención y el procedente del derecho francés y, seguido, en parte, por el Código de 1885, que se decantaba por el depósito y venta ${ }^{88}$. Sin embargo, este Código sí permitía el derecho de retención del equipaje del pasajero como garantía del pago del precio y de los gastos de manutención, con preferencia frente a otros acreedores, en caso de venta, como si se tratara de fletes ${ }^{89}$.

expertos si no se recepcionaban porque estaban en mal estado por culpa del patrón, adjudicándose el flete por provisión [VAlin, R. J., cit. (n. 29), I, pp. 625-626].

82 Código de Comercio de 1885, art. 665.

${ }^{83}$ Código de Comercio de 1885, arts. 666 y 667. Por tanto, se otorgaba al fletante un privilegio que le aseguraba el recibo del flete, pero no se le concedía ningún derecho de prenda sobre las mercancías.

${ }^{84}$ Ley 14/2014, de 24 de julio, de Navegación Maritima, art. 236.

${ }^{85}$ Código de Comercio de 1885, art. 668.1. También se podían vender los bienes cuando había riesgo de deterioro o su conservación y custodia suponían gastos excesivos (Código de Comercio de 1885, art. 668.2).

${ }^{86}$ Ley 14/2014, de 24 de julio, de Navegación Marítima, art. 237. Tanto este artículo como el 236 se aplican al equipaje de bodega (el entregado al porteador) (Ley 14/2014, de 24 de julio, de Navegación Marítima, art. 296). Cfr. Ley 14/2014, de 24 de julio, de Navegación Marítima, art. 255 .

${ }^{87}$ Ley 14/2014, de 24 de julio, de Navegación Maritima, art. 238.

${ }^{88}$ Respecto al depósito y venta, aplicable no solo a las mercancías sino tambien a los equipajes, cuando el destinatario no abone el flete, el pasaje y otros gastos o no se presente a recoger los géneros o cuando no se pueda concluir el viaje por causa sobrevenida, ver Ley 14/2014, de 24 de julio, de Navegación Marítima, arts. 512-514.

${ }^{89}$ Código de Comercio de 1885, art. 704. Según Fariña, esta disposición no tendría aplicación 


\section{INCUMPLIMIENTO CONTRACTUAL/IMPOSIBILIDAD DE EJECUTAR EL CONTRATO: REPERCUSIÓN RESPECTO A LA} OBLIGACIÓN DE PAGO

Los diversos textos que hemos examinado regulan, en mayor o menor medida, las consecuencias del incumplimiento contractual de cualquiera de las partes, ya sea atribuible o no a las mismas, y de aquellos supuestos en los que el contrato se rescinde y no llega a ejecutarse, sobre todo respecto al fletamento, aunque lo dispuesto sea extrapolable, la mayoría de las veces, al pasaje. De ahí que, de nuevo, efectuemos un tratamiento unitario. Como, en otras ocasiones, la regla obliga a acudir, en primer lugar, a la voluntad reflejada en el contrato. En su defecto, la ley, históricamente, imponía sanciones diversas que iban desde las penas corporales o privativas de libertad hasta las económicas destinadas, normalmente, a la parte perjudicada por el incumplimiento ${ }^{90}$. Estas últimas solían consistir en una indemnización o estar directamente relacionadas con el precio del contrato, imponiendo su exención, reducción o devolución, si ya había sido pagado, siendo este un principio indiscutible, del que nos vamos a ocupar. No obstante, su concreción y cuantía van a depender de las circunstancias que rodean cada cuerpo legislativo, en función del momento histórico y de las características de la navegación en cada época, siendo, a veces, necesario acudir a los tribunales, aunque era preferible una solución arbitral ${ }^{91}$.

Ya en el Código de Manú, el incumplimiento de las condiciones de lugar y tiempo pactadas en el transporte de mercancías tenía como consecuencia directa que el transportista no recibiese el precio fijado ${ }^{92}$, "mais celui qui sera fixé par des experts ${ }^{93}$. Siendo evidente que la obligación principal de aquel era trasladar la carga

en la práctica ya que las compañías suelen exigir el pago anticipado del billete [FARIÑA, Francisco, Derecho y Legislación maritimos (Madrid, Luis Pamies, 1951), p. 236]. No obstante, esto no impide su consideración como principio con base histórica. El pasajero se consideraba cargador de sus efectos personales y el capitán no respondía de lo que aquel tenía bajo su custodia, salvo que el daño proceda de él o de la tripulación (Código de Comercio de 1885, art. 703).

${ }^{90}$ Los Capitols del Rei en Pere tenían una disposición genérica por la que se sancionaba el incumplimiento contractual de un "mariner o balester o servicial et altre", con una una multa de cien sueldos o con pena de prisión de cien días salvo causa justificada como enfermedad, matrimonio o herencia sobrevenida, que tenía que ser comunicada a la otra parte devolviendo lo que hubiese recibido, si era el caso (Capitols del Rei en Pere, I). Según interpretación de Serna Vallejo que compartimos, la norma comprendía cualquier incumplimiento de las obligaciones contraídas por los que concertaban "su incorporación a la nave, como tripulante, comerciante o simple viajero" y, por tanto, el incumplimiento del pasajero o del mercader [SERNA VALLEJO, Margarita, Las previsiones penales y procesales maritimas de los Capitols del Rei en Pere de 1340 incluidos en el LCM, en Mundos Medievales: espacios sociedades y poder. Homenaje al profesor José Angel García de Cortázar y Ruiz de Aguirre (Santander, Editorial de la Universidad de Cantabria, 2012), II, p. 1910].

91 Ashburner, Walter, cit. (n. 14), p. CCV.

${ }^{92}$ Mânava Dharma Sâstra, VIII, sloka 156 [Jones, W., cit. (n. 9), p. 210; LoIseleur DeSLONGCHAmps, A., cit. (n. 9), p. 274; BüHLER, G., cit. (n. 9), p. 281; STREhly, G., cit. (n. 9), p. 221 y Pardessus, J. M., cit. (n. 9), VI, p. 385].

${ }^{93}$ Loiseleur Deslongchamps, A., cit. (n. 9), p. 274. Para Pardessus, se trata de una regla basada en el Derecho natural común a todas las legislaciones, aunque limita el objeto a las 
o al pasajero y su equipaje indemnes ${ }^{94}$ al lugar de destino, si no lo hacía lo lógico era que no pudiese exigir el precio y que devolviese lo que cobró por adelantado ${ }^{95}$.

Siglos después, en el Código de Comercio español de 1885, el principio general sobre el pago del flete radica en la concepción del fletamento como arrendamiento de obra; de modo que se abonaba según el éxito de la aventura marítima: entero cuando el buque llegaba a su destino; y en proporción a la distancia recorrida si se perdía antes ${ }^{96}$. La Ley de Navegación Marítima de 2014 opta por sancionar el incumplimiento en el contrato de fletamento con una indemnización de los

mercancías y lo circunscribe al transporte por mar al recoger la disposición en su colección de leyes marítimas [Pardessus, J. M., cit. (n. 9), VI, p. 386, n. 1]. Pese a que no son pacíficas las interpretaciones, entendemos que la norma podría ser aplicable, por analogía, al pasaje marítimo. Según la traducción de Jones de los comentarios de Kullûka, el precepto se dirigía al transporte de mercancías en un vehículo con ruedas a cambio de un "interés" (tchakra vr ddhi) entendido como precio [Jones, W., cit. (n. 9), p. 210]. En idéntico sentido, Bühler, en su traducción, reconduce la norma al transporte terrestre de mercancías [BÜHLER, G., cit. (n. 9), p. 281]. De "transport par voiture», habla Strehly sin concretar si lo que se transportan son personas o mercaderías [Strehly, G., cit. (n. 9), p. 221). Por su parte, Loiseleur Deslongchamps concreta el objeto del transporte en las mercancías aunque no delimita si es marítimo o terrestre [LOISELEUR DeslongChamps, A., cit. (n. 9), p. 274].

${ }^{4}$ En las Costums de Tortosa, el señor de la nave debía devolver el flete al pasajero si no cumplía con su obligación de proteger sus bienes y su persona, defendiéndolo frente a la tripulación, a corsarios y frente a cualquiera que pretendiese dañarlo (Costums de Tortosa, IX, 27, 18, párrafos 1 y 2). Según este texto, el patrón tenía un deber general de proteger la embarcación y todos los objetos que recibía en la misma, tanto los que integraban la carga como las pertenencias de los pasajeros (mercancías o altres coses), debiendo indemnizar si se dañaban (Costums de Tortosa, II, 17, 1, párrafo 1) y respondiendo de esta indemnización con el flete (tras deducir los salarios de los marineros y lo preciso para su alimentación y necesidades básicas), con la nave y, finalmente, con su propia persona y patrimonio si lo anterior no era suficiente (Costums de Tortosa, IX, 27, 20, párrafo 2). Cfr. Costums de Tortosa, IX, 27, 8.

${ }_{95}$ Este principio estaba presente en el Digesto [D. 19, 2, 15, 6 (Ulp. 32 ad ed.)] y en diversos textos de derecho bizantino. No obstante, pese a su obviedad, Ashburner duda de que

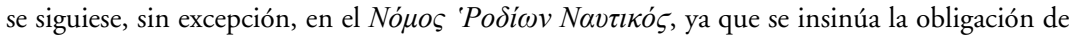
abonar flete (al menos la mitad) cuando la nave se perdía una vez cargada. Para armonizar estas reglas, propone dos posibilidades; considerar que el Digesto se refería a la parte del precio que debía pagarse al finalizar el contrato y se adelantaba; o suponer que el Digesto contemplaba los casos de pérdida de los géneros por culpa del transportista y la compilación rodia aquellos en los que este no tenía responsabilidad [Ashburner, Walter, cit. (n. 14), pp. CXCVI-CXCVII]. Nos decantamos por la segunda opción, ya que si el transportista incumplía voluntariamente con su obligación no debía cobrar nada y, además, los textos parecen vincular la pérdida del buque a circunstancias meteorológicas adversas y, en cualquier caso, el flete debería referirse solo a los bienes salvados. No obstante, Ashburner cree más satisfactoria la solución de los Estatutos de Ancona de 1397: si los géneros se perdían no se pagaba flete, pero el ya pagado no se podía recuperar [Statuti anconitati del mare, rúb. LVIII, edición de PARDESSUS, J. M., Collection de lois maritimes antérieures au XVIII siècle (Paris, L'Imprimerie Royale, 1839), V, p. 169]. Cfr.

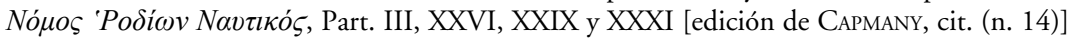
y XXVII, XXX y XXXII [ediciones de PARdessus y Ashburner, cits. (n. 14)].

96 Código de Comercio de 1885, art. 659, in fine y art. 657, in fine. Sin embargo, indica Garrigues que estas normas apenas se aplicaban ya que el fletante solía incluir en el contrato la cláusula "flete devengado a todo evento", es decir, incluso cuando las mercancías no llegaban a su destino. Considera válida esta estipulación en base al art. 661 in fine que permite pactar la no devolución del flete pagado por adelantado, aun cuando se perdiesen los géneros. Concluye 
daños y perjuicios y con el derecho a resolver el contrato, aunque también prevé algunas consecuencias en relación al flete; siendo mayores las repercusiones en el precio cuando el incumplimiento afecta al pasaje ${ }^{97}$.

Como decíamos, la ejecución del contrato de transporte marítimo tanto de mercancías como de personas podía verse interrumpida, modificada o imposibilitada por decisión o voluntad de una de las partes contractuales o por motivos ajenos a las mismas. En este sentido, Ashburner distinguía entre un incumplimiento voluntario y otro involuntario. En términos generales, en el primer caso, habría que acudir al contrato para comprobar si se había pactado la remisión a las normas generales para concretar las consecuencias o si se había estipulado una cláusula penal para sancionar dicho supuesto ${ }^{98}$. Repasamos, a continuación, la infracción de algunas obligaciones concretas que alteraban el devenir contractual, con repercusión en el flete, que hemos descubierto en los textos históricos, cuyas reglas se han mantenido en el tiempo, distinguiendo después entre el desistimiento voluntario y las hipótesis de incumplimiento involuntario.

\section{Infracciones relacionadas con la obligación de embarcar (géneros o pasajeros) en las condiciones pactadas}

$\mathrm{Al}$ margen de los casos en los que no se cargaban los bienes o el pasajero no embarcaba por decisión de cualquiera de las partes y que incluimos en el desistimiento voluntario, nos ocupamos de infracciones concretas relacionadas con la obligación de embarcar que modificaban (sin llegar a impedir, la mayoría de las veces) la ejecución del contrato. Un posible incumplimiento por parte del mercader, en relación a esta obligación, era que cargase menos géneros de los pactados en el contrato. En este supuesto, según la compilación rodia, debía pagar también el flete de lo que faltase ${ }^{99}$, lo que se mantiene como principio en la legislación histórica, salvo alguna excepción ${ }^{100}$. Así, lo mismo se disponía en las Costums de

que la cláusula supondría "un desplazamiento de la carga del seguro" [GARRIGUES, Joaquín, cit. (n. 8), II, 2, p. 771].

${ }^{97}$ Así, cualquier "modificación importante" en horarios, condiciones de comodidad, plaza adquirida, escalas o desviación de la ruta pactada, da derecho al pasajero, si decide resolver el contrato, a exigir la devolución del precio total o de la parte proporcional que corresponda al trayecto que falte por realizar y a una indemnización de daños y perjuicios, salvo que el cambio tuviese causa justificada [Ley 14/2014, de 24 de julio, de Navegación Marítima, art. 297.c)].

${ }^{98}$ Muchas veces, el contrato reproducía lo establecido en la ley como sanción por su inobservancia. Además, hay que tener en cuenta que las condiciones históricas de la navegación distaban bastante de las actuales y las travesías de larga duración debían comenzar en unos meses concretos para que se pudiesen completar en condiciones meteorológicas favorables. Si en este periodo no se entregaba la carga o el pasajero no embarcaba, la consecuencia podía ser no un simple retraso sino la imposibilidad de realizar el viaje. En tal caso, lo lógico era sancionar este incumplimiento con el pago del flete completo junto a otras indemnizaciones en base a las expectativas comerciales del transportista (lucro cesante). Por el contrario, si el trayecto era corto, la renuncia antes de iniciarlo implicaría solo el abono de la parte proporcional del flete [AsHBuRner, Walter, cit. (n. 14), pp. CCI-CCVIII].

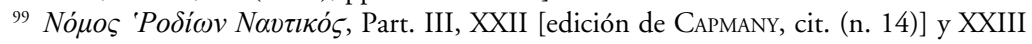
[ediciones de Pardessus y AshbuRner, cits. (n. 14)].

${ }^{100}$ En las Ordenanzas de Trani de 1063 si el mercader no entregaba todos los géneros debía 
Tortosa ${ }^{101}$, en el $L C M^{102}$, en la Ordenanza de la Marina de $1681^{103}$, en el Código de Comercio francés de $1807^{104}$, en el español de 1885 y en la Ley de Navegación Marítima de 2014 aunque estos dos últimos cuerpos legales eximen al fletador de pagar el flete de lo no embarcado cuando el capitán consiga otros bienes para completar la capacidad del buque ${ }^{105}$.

Por otra parte, la Ordenanza de 1681 establecía que si el mercader fletaba la nave completa y no usaba el espacio disponible, el patrón solo podía cargar otros géneros si aquel lo permitía y, en tal caso, debía hacerle partícipe del flete ${ }^{106}$. En idéntico sentido, se pronunciaba el Código de Comercio de $1807^{107}$. El capitán respondía de los perjuicios ocasionados al que no podía embarcar los bienes pactados cuando declaraba falsamente una capacidad superior ${ }^{108}$. La misma regla, procedente del $L C M^{109}$, se contiene en el Código de Comercio francés ${ }^{110}$ y similar, en el español de $1885^{111}$.

pagar la cuarta parte del flete [Ordinamenta et consuetudo maris edita per consules civitatis Trani, VII, edición de PARDESSUS, cit. (n. 95), V, pp. 239-240].

${ }^{101}$ Costums de Tortosa, IX, 27, 37. Se obligaba al patrón a someterse al contrato y a transportar las quintaladas convenidas, independientemente del flete (tanto si era elevado como bajo, aunque dependería de las mismas), sin que se pudieran introducir más de las pactadas, salvo que se llegase a un nuevo acuerdo (Costums de Tortosa, IX, 27, 28).

${ }^{102}$ LCM, cap. CII, edición de ParelLadA, cit. (n. 26), p. 49 y cap. LVII [102], edición de PARDEssus, cit. (n. 26), II pp. 107-108.

${ }^{103}$ Ordonnance touchant la marine du Mois d'Août 1681, lib. III, tít. 3º, art. 3. Cfr. PARDEssus, J. M., Cours, cit. (n. 34), III, pp. 171, 174 y 178-179; Pothier, R. J., cit. (n. 29), p. 74 y VALIN, R. J., cit. (n. 29), I, pp. 608-609.

104 Code de commerce de 1807, art. 288.

${ }^{105}$ Código de Comercio de 1885, art. 680 (se indica que si el capitán completaba la carga el fletador solo abonaba la diferencia si había) y Ley 14/2014, de 24 de julio, de Navegación Maritima, art. 230. Sería el flete sobre vacío.

106 Ordonnance touchant la marine du Mois d'Aô̂t 1681, lib. III, tít. 3º, art. 2. Ver Pardessus, Jean Marie, Cours, cit. (n. 34), III, p. 165 y Fernández-Guerra Fernández, Ramón, cit. (n. 58), p. 127.

${ }_{107}$ Code de commerce de 1807, art. 287.

${ }_{108}$ Ordonnance touchant la marine du Mois d'Août 1681, lib. III, tít. 3º, art. 4. Solo se estimaba un error superior a la cuadragésima parte, considerándose que uno inferior no implicaba mala fe por estar dentro de lo normal (Ordonnance touchant la marine du Mois d'Août 1681, lib. III, tít. 30, art. 5). Véase Pardessus, J. M., Cours, cit. (n. 34), III, pp. 165-166 y Valin, R. J., cit. (n. 29), I, pp. 607, 609 y 610-611. Cfr. Code de commerce de 1807, art. 290.

${ }^{109}$ Cuando el capitán no podía cumplir con su obligación de transportar los géneros pactados, debía proporcionar a los mercaderes un buque similar o de categoría superior, pagando la diferencia cuando el flete era más elevado al inicialmente convenido, siempre que aquellos aceptasen esta compensación, ya que, normalmente, los patrones solían engañar sobre la capacidad de la nave en un tercio o un cuarto [ $L C M$, cap. CLXXXIV, edición de PARELLADA, cit. (n. 26), p. 79 y CXXXXIX (184), edición de PARDESSus, cit. (n. 26), II, p. 154]. Otra opción era que se rebajasen los fletes en proporción a lo que realmente se podía transportar [ $L C M$, cap. CLXXXV, edición de Parellada, cit. (n. 26), p. 79 y CXL (185), edición de Pardessus, cit. (n. 26), II, pp. 154-155].

${ }_{110}$ Code de commerce de 1807, art. 289.

111 Si había error o engaño en la capacidad del buque y un solo fletador que no optaba por la rescisión, tenía derecho a la reducción del flete proporcional a lo que no pudiese cargar, además de recibir la correspondiente indemnización (Código de Comercio de 1885, art. 669). 
A sensu contrario, si en la nave se cargaban más géneros de los convenidos se debía pagar por el exceso, como penalización, aunque los criterios para determinar la cuantía difieren según las normas ${ }^{12}$. La regla genérica era que había que declarar la totalidad de bienes que se introducían en el buque, ya que no se podía embarcar nada sin el consentimiento del capitán. La declaración se hacía, en principio, ante el escribano y tenía que constar en el conocimiento de embarque cuando este se generaliza. Las Costums de Tortosa incluyen esta obligación entre los deberes de los cargadores (extensible a los pasajeros), exigiéndose la inscripción en el Cartulario $^{113}$. Una vez que la nave había zarpado era obligatorio manifestar todos los géneros embarcados y pagar flete por ellos aunque no estuviesen recogidos en el contrato (aunque, en principio, habría que limitarse a los mismos, salvo nuevo acuerdo), debiendo abonarse por los no declarados el flete más alto que se hubiese pagado en el viaje $\mathrm{e}^{114}$. El $L C M$ disponía que si el mercader se excedía en la carga respecto a lo pactado, sin ponerlo en conocimiento del patrón, este podía exigirle los fletes que quisiera ${ }^{115}$ y si sospechaba, tras haber visto los bultos o fardos (sin haberse fletado a quintaladas) que había introducido algo más le podía exigir un juramento ante la justicia que debía creer salvo que descubriese pruebas en contra, sancionándose, tal supuesto, con el doble del flete del exceso de mercancías ${ }^{116}$. Una vez que zarpaba la nave, el fletador estaba obligado a manifestar al escribano cualquier género que no hubiese sido inscrito previamente y si se localizaba algo no declarado debía pagar el precio más alto que se hubiese abonado en el buque en proporción al número de quintaladas, sin derecho a indemnización en caso de pérdida ${ }^{117}$; pero si se hallaba en el momento de la descarga el capitán tenía derecho a exigir el flete que estimase oportuno y el mercader debía pagarlo sin objeción alguna $^{118}$. Lo mismo establecía la Ordenanza de la Marina de 1681 que utilizaba como referente mercancías de la misma calidad que las no declaradas permitiendo que el patrón reclamase el importe más elevado que se hubiese pagado por las mismas o el señalado por un experto si no las había ${ }^{119}$. De otro lado, el

${ }^{112}$ Algunos Estatutos, como el de Ragusa, lo cifran en el duplo de lo pagado por los restantes bienes y otros, en el doble de la tarifa más alta [ASHBurner, Walter, cit. (n. 14), p. CXCIV]. En cuanto a la obligación de abonar el duplum por el exceso, ver Estatutos de Zara, IV, 30, edición de Pardessus, Jean Marie, cit. (n. 9), VI, p. 612.

113 Costums de Tortosa, IX, 27, 9 y 28.

114 Costums de Tortosa, IX, 27, 38.

${ }^{115}$ LCM, cap. LXXXVII, edición de Parellada, cit. (n. 26), p. 38 y XLII [87], edición de Pardessus, cit. (n. 26), II, p. 87. Cfr. LCM, cap. CLXXXVII, edición de Parellada, cit. (n. 26), pp. 80-81 y CXLII [187], edición de PARdessus, cit. (n. 26), II, pp. 156-157 y LCM, cap. CCLXXXI, edición de Parellada, cit. (n. 26), pp. 170-171 y CCXXXVI [281], edición de Pardessus, cit. (n. 26), II, pp. 315-317.

${ }^{116}$ LCM, cap. CCLXXXI, edición de Parellada, cit. (n. 26), pp. 170-171 y CCXXXVI [281], edición de Pardessus, cit. (n. 26), II, pp. 315-317.

${ }^{117}$ LCM, cap. C, edición de Parellada, cit. (n. 26), p. 48 y LV [100], edición de Pardessus, cit. (n.26), II, p. 106.

${ }^{118}$ LCM, cap. CXV, edición de Parellada, cit. (n. 26), pp. 54-55; cap. CXIV, edición de Capmany, cit. (n. 26), p. 100 y cap. LXX [115], edición de PARDEssus, cit. (n. 26), II, p. 117.

119 Ordonnance touchant la marine du Mois d'Aô̂t 1681, lib. III, tít. 3º, art. 7. Ver Code de commerce de 1807, art. 292. Según Valin la declaración del capitán podía sustituir el co- 
flete se incrementaba en proporción al sobrante de géneros embarcados ${ }^{120}$. Del precio más alto pactado para aquel viaje hablaba el Código de Comercio español de 1885 para aludir al flete que podía cobrar el capitán si decidía transportar las mercancías embarcadas clandestinamente (si podía hacerlo con buena estiba), en lugar de descargarlas antes de salir. Se admitía que el fletador cargase más géneros que los contratados, siempre que pagase el exceso de flete según el precio acordado en el contrato y no afectase a las condiciones de estiba ${ }^{121}$. En línea similar, la Ley de Navegación Marítima de 2014 prohíbe el embarque clandestino de mercancías de distinta clase a la acordada, salvo que se pueda hacer sin perjuicio para el porteador y los demás cargadores, pudiéndose reclamar el "flete que corresponda usualmente” al género embarcado. De darse este supuesto, el fletador responde de los daños y perjuicios que pueda ocasionar, con independencia de su obligación de pagar el flete ${ }^{122}$.

Directamente relacionada con la obligación de embarcar, se encontraba la de hacerlo en el tiempo establecido no ocasionando retrasos. Sin entrar en otras responsabilidades y ciñéndonos en exclusiva en lo relativo al flete, el Nó $\mu o \varsigma$

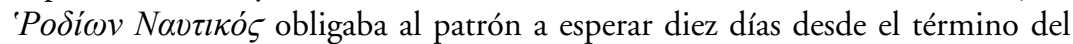
plazo pactado en el contrato. Transcurrido este periodo, podía iniciar libremente la travesía y exigir todo el flete, salvo que el cargador que se demoraba pagara un precio superior o una indemnización ${ }^{123}$. Esto podría aplicarse también al pasajero que no se presentaba a tiempo para el embarque. En las Actes génois d'Arménie los mercaderes satisfacían un flete extra si incumplían cualquier término contractual, incluida la estipulación de cargar en el plazo fijado ${ }^{124}$. Los Estatutos de Marsella señalaban que cualquier retraso en la carga no imputable al dueño de las mercancías era responsabilidad del armador, si estaba en la nave, o del capitán, en caso contrario, debiendo ser devuelto el precio si ya se había cobrado y no se realizaba el viaje $^{125}$. El $L C M$ imponía al patrón el pago a los mercaderes del exceso de flete cuando estos se veían forzados a fletar otro buque a un precio más elevado por incumplimiento de aquel de su compromiso de tener la nave disponible en el periodo acordado. Ahora bien, si la imposibilidad de cumplir el plazo no era

nocimiento de embarque cuando este no se pudo formalizar. Igualmente habría que proceder respecto a los bienes que estaban dentro de baúles, que solían pertenecer a los pasajeros (y de los que no hacía conocimiento), si sus dueños mostraban su contenido [VALIN, R. J., cit. (n. 29 ), II, pp. 188-189]. Cfr. Pardessus, J. M., Cours, cit. (n. 34), III, p. 167 y Lyon-CaEn, C. y Renault, L., cit. (n. 32), V, p. 498.

${ }^{120}$ Ordonnance touchant la marine du Mois d'Août 1681, lib. III, tít. 3º, art. 3.

121 Código de Comercio de 1885, art. 674.

122 Ley 14/2014, de 24 de julio, de Navegación Marítima, art. 231

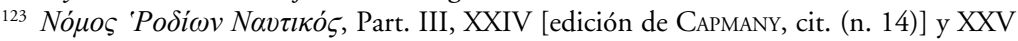
[ediciones de Pardessus y de Ashburner, cits. (n. 14)]. Se trataba de "diez días de gracia" que se concedían al mercader una vez transcurrido el plazo contractual para embarcar [AsHBURNER, Walter, cit. (n. 14), pp. CLXXXVII y 103-105]. Capmany parece interpretar que para exigir el flete completo debían pasar "otros diez días".

124 Ashburner, Walter, cit. (n. 14), pp. CLXXXVII-CLXXXVIII.

125 Statuta civitatis Massiliae, lib. IV, cap. XXI, edición de PARDESsus, Jean Marie, cit. (n. 16), IV, p. 276 y DE Fresquet, Raimond Frédéric, cit. (n. 16), pp. 138-139. 
atribuible al capitán, los mercaderes debían entregar la carga y si no lo hacían tenían que satisfacer los fletes convenidos ${ }^{126}$. En la Ordenanza de la Marina de 1681, si el fletamento se había contratado para un viaje de ida y vuelta y la nave era retenida durante la travesía o en el puerto de descarga por culpa del fletador, este debía pagar el flete completo y los gastos, daños y perjuicios de la demora ${ }^{127}$. En función de la reciprocidad, correspondía al capitán indemnizar al mercader si la retención o el retraso en la ejecución del contrato eran por su falta de diligencia $^{128}$. El Código de Comercio español de 1885 reconocía el derecho del pasajero a permanecer a bordo y a ser alimentado cuando el buque retrasaba su salida, salvo que se debiera a caso fortuito o fuerza mayor. No obstante, si el retraso excedía de diez días podía exigir la devolución del pasaje y una indemnización por los daños y perjuicios cuando era exclusivamente por culpa del transportista ${ }^{129}$. En el fletamento, el fletador que no situaba la carga en el costado, cumplido el término de las sobreestadías, debía abonar la mitad del flete pactado, facultando al fletante a rescindir el contrato ${ }^{130}$. Si se había acordado cargar en otro puerto y no se entregaban los géneros, transcurridos los plazos previstos, el capitán debía regresar al lugar donde se formalizó el contrato y el fletador tenía que pagar el total del flete, estableciéndose lo mismo si se había fletado para un viaje de ida y vuelta y no se suministraba el cargamento para el retorno ${ }^{131}$. La Ley de navegación marítima de 2014 recoge el derecho a una limitación de la responsabilidad por retraso, no de la carga sino del viaje en general, fijándose en una cantidad "equivalente a dos veces y media el flete pagadero por las mercancías afectadas" por la demora, sin que exceda del flete total a pagar, aunque el porteador o sus auxiliares no podrían ejercer este derecho cuando hayan ocasionado el retraso de modo intencionado o temerario y "con conciencia de su probabilidad"132. También puede el porteador exigir el flete sobre vacío que corresponda cuando transcurre el periodo de demoras sin haber terminado la carga y decide comenzar el viaje con los géneros cargados hasta el momento ${ }^{133}$.

${ }^{126}$ LCM, cap. CCLX, edición de Parellada, cit. (n. 26), pp. 144-145 y cap. CCXV [260], edición de Pardessus, cit. (n. 26), II, pp. 266-269.

127 Ordonnance touchant la marine du Mois d'Août 1681, lib. III, tít. 3º, art. 9. Cfr. POTHIER, Robert Joseph, cit. (n. 29), pp. 75 y 80-81. Esta norma se reproduce en Code de commerce de 1807, art. 294, donde se indica que la nave podía hacer el viaje de vuelta sin carga o con la carga incompleta, debiéndose, en cualquier caso, el total del flete.

${ }^{128}$ Ordonnance touchant la marine du Mois d'Août 1681, lib. III, tít. 3º, art. 10. La negligencia del capitán que causaba la demora se podía concretar en realizar escalas no previstas o innecesarias, falta de documentación o incumplimiento de los requisitos formales para la descarga [VALIN, René Josué, cit. (n. 29), I, pp. 616-617]. El Code de commerce de 1807, art. 295 precisaba que el hecho podía suceder en la travesía o en el lugar de descarga y los daños e intereses eran tasados por expertos. Cfr. Pardessus, Jean Marie, Cours, cit. (n. 34), III, pp. 137, 167-168, 174 y 177.

${ }_{129}$ Código de Comercio de 1885, art. 698.2.

${ }_{130}$ Código de Comercio de 1885, art. 689.1.

131 Código de Comercio de 1885, art. 675. En este caso y en el del artículo anterior podríamos estar ante un desistimiento voluntario si no se llegaba a entregar la carga y la travesía no se realizaba.

${ }^{132}$ Ley 14/2014, de 24 de julio, de Navegación Maritima, art. 283.

133 Ley 14/2014, de 24 de julio, de Navegación Marítima, art. 243. 


\section{Desistimiento voluntario del contrato}

La mayor parte de los textos remiten al contrato para determinar las consecuencias del desistimiento voluntario, distinguiendo si tenía lugar antes o después de cargar el buque o de comenzar el viaje. Así, la compilación rodia disponía que cuando el fletamento se hacía en escritura, había que acudir, en primer término, a las cláusulas penales recogidas en la misma, para sancionar el incumplimiento. En caso contrario, la parte que incumplía debía indemnizar a la otra con la mitad del flete pactado, salvo que ya se hubiese empezado a cargar la nave, porque, en tal supuesto, había que pagar la totalidad del flete ${ }^{134}$, al igual que si el mercader desembarcaba sus bienes antes de iniciar la travesía ${ }^{135}$, suponiendo que no existiese ningún motivo y se hubiera realizado toda la carga ${ }^{136}$. Más precisa era la regulación del Constitutum usus de Pisa de 1160 y de los Estatutos de Marsella de 1253-1255. Cuando, sin causa justificada, el mercader no cargaba las mercancías en el lugar y tiempo convenidos debía abonar todo el flete; salvo que el armador no perdiese el viaje, es decir, que volviera a fletar el buque; en este caso, solo pagaría la diferencia entre el precio acordado y el nuevo. Pero si había cláusula penal en el contrato, se debía cumplir siempre que no consistiese en el pago de una cantidad superior al doble del flete estipulado ${ }^{137}$. Los Estatutos de Ancona de 1397 sancionaban al fletador que no embarcaba los géneros pactados, en todo o en parte, con el precio completo ${ }^{138}$.

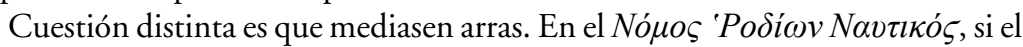
mercader fletaba una nave adelantando parte del precio y, finalmente, no efectuaba el viaje perdía dicha cantidad y si era el patrón el que no cumplía se le penalizaba

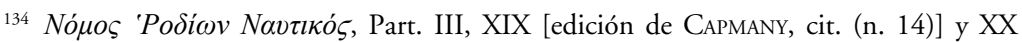
[ediciones de Pardessus y de Ashburner, cits. (n. 14)]. Ashburne propone otra interpretación de la norma (un tanto forzada): que fuese referida a establecer las condiciones del momento del pago, de modo que el mercader abonaba la mitad al entregar la carga (y si el patrón no cumplía devolvía dicha cantidad) y el precio completo al finalizar la travesía cuando llevase a cabo la descarga. Afirma que el contrato de fletamento tenía que hacerse por escrito y estar suscrito por ambas partes, ya que, de lo contrario, carecía de validez y la disposición iba referida no a la ausencia de escritura sino de cláusulas penales en la misma cuya inclusión dependía de la voluntad de las partes [Ashburner, Walter, cit. (n. 14), pp. CCII y 100]. No obstante, las traducciones de Pardessus y Capmany parecen admitir el contrato sin escritura. Capmany no habla de que se hubieran empezado a cargar los géneros sino de que el fletador "rehusase" a embarcarlos.

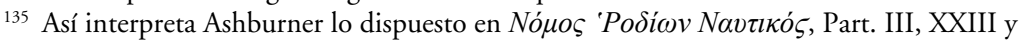
XXV, de su edición; así como en D. 14, 2, 10, 2 (Lab. 1 pith. a Paul. epit.). Véase Ashburner, Walter, cit. (n. 14), pp. 98-101.

136 No obstante, otros textos sancionan estos casos con el abono de la mitad del flete [Ordinamenta et consuetudo maris edita per consules civitatis Trani, VI, edición de PARDESSUs, Jean Marie, cit. (n. 95), V, p. 239. Ver también las Ordenanzas de Trani en Twiss, Travers (ed.), The black book of the Admiralty with an appendix (4 volúmenes, London, Longman \& Co., 1871-1876, volumen IV, 1876), pp. $522-544$ (reimp., Wiesbaden, Kraus Reprint, 1965)].

137 Constitutum usus, rúb. XIII, de naulo navium, edición de PARDESSUs, J. M., cit. (n. 16), IV, pp. 574-575 y Statuta civitatis Massiliae, lib. IV, cap. VIII, edición de PARDESsus, J. M., cit. (n. 16), IV, p. 270. Sobre el incumplimiento contractual previsto en los Estatutos de Marsella y sus consecuencias, cfr. DE FRESQUET, R. F., cit. (n. 16), p. 138.

138 Statuti anconitati del mare, rúb. XXVIII y rúb. LI, edición de PARDESSUS, J. M., cit. (n. 95), V, pp. 141 y 164-165. 
con la devolución del doble de lo que había recibido como señal ${ }^{139}$. Para conciliar esta disposición con lo anterior y en aras a la justicia, consideramos acertada la precisión de Ashburner en el sentido de que la norma solo se aplicaría cuando ninguna de las partes había iniciado la ejecución del contrato ${ }^{140} \mathrm{o}$, en palabras de Pardessus, cuando estuviésemos ante una simple promesa y no ante un contrato perfeccionado en el que habría que atenerse a las sanciones antes comentadas ${ }^{141}$. Otros textos medievales permitían optar entre devolver el doble o una indemnización de los daños y perjuicios, cuando se habían entregado arras y el armador incumplía intencionadamente. Pero, si era el mercader el que no cumplía debía abonar lo que faltase hasta completar el flete, una vez descontadas las arras ${ }^{142}$.

Respecto a los cargadores, las Costums de Tortosa contemplaban la posibilidad de que rescindiesen el contrato o dejasen de cumplirlo de forma voluntaria desistiendo del transporte ${ }^{143}$. Si el desistimiento tenía lugar antes de que se iniciara la navegación pero una vez comenzada la carga y el naviero había destinado la mitad del espacio disponible a la misma y dispuesto la tripulación al respecto, se obligaba al mercader a pagar la mitad del precio pactado ${ }^{144}$. Si no había empezado la carga y el naviero había fletado menos de la mitad de la capacidad del buque y de la tripulación, el fletador que renunciaba a la travesía tan solo debía indemnizar los daños y perjuicios causados ${ }^{145}$.

Según el $L C M$, si el mercader decidía fletar una nave distinta que le ofrecían a un precio inferior y en condiciones más ventajosas, incumpliendo el contrato, tenía que indemnizar al patrón del primer buque por los perjuicios ocasionados y entregarle la carga pactada y, si no lo hacía, debía abonarle el total del flete inicialmente estipulado ${ }^{146}$. En el fletamento a quintaladas, el fletador que desistía

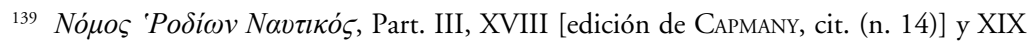
[ediciones de Pardessus y de Ashburner, cits. (n. 14)].

${ }_{140}$ Ashburner, Walter, cit. (n. 14), p. CCVII.

141 Opina que sería una "promesa acompañada de arras", siguiéndose los principios de derecho romano en materia de compraventa, siendo discutible su extensión a los arrendamientos [PARdessus, J. M., cit. (n. 14), I, p. 248, n. 1 y 2].

${ }^{142}$ Constitutum usus, rúb. XIII, de naulo navium, edición de Pardessus, J. M., cit. (n. 16), IV, pp. 575-576 y Statuta civitatis Massiliae, lib. IV, cap. IX, edición de PARDESSUs, J. M., cit. (n. 16), IV, pp. 270-271.

${ }^{143}$ El desistimiento voluntario implicaba, al igual que en la legislación rodia, una sanción debiendo el cargador abonar al naviero una cantidad como pena que variaba según el caso [OLIVER, Bienvenido, cit. (n. 23), III, p. 290]. Lo mismo se podría aplicar al pasajero que rescindía el contrato unilateralmente y sin causa.

144 Costums de Tortosa, IX, 27, 25. En este caso, los marineros cobrarían la mitad de su salario.

145 Costums de Tortosa, IX, 27, 26, párr. 4. Aquí los marineros recibían la parte proporcional de su sueldo. Por otro lado, los cargadores podían retirar los géneros sin pagar flete por ellos, sustituyéndolos por otros similares (de igual calidad y peso), siempre que la nave estuviese fondeada y no provocasen retrasos ni perjuicios, sin que se viese afectado el salario de los marineros (Costums de Tortosa, IX, 27, 26, párr. 2). Ver Oliver, Bienvenido, cit. (n. 23), III, p. 288.

${ }^{146}$ LCM, cap. CCLXV, edición de Parellada, cit. (n. 26), pp. 152-153 y cap. CCXX [265], edición de Pardessus, cit. (n. 26), II, pp. 283-284. También se debía todo el flete si el viaje no se hacía por la venta previa de las mercancías cuyo transporte se había contratado, evitando que los mercaderes se lucren y el patrón se viese perjudicado [ $L C M$, cap. LXXXV, edición de Parellada, cit. (n. 26), p. 37 y XL [85], edición de Pardessus, cit. (n. 26), II, pp. 85-86]. 
estaba obligado a compensar al capitán los gastos realizados en función del viaje contratado siempre que la renuncia se produjese antes de comenzar la carga y si esta se había iniciado, tenía que pagar la mitad del flete convenido, con independencia de que se hubiese embarcado la totalidad o una parte; y un tercio, si los géneros se habían trasladado al muelle aunque no se hubiesen empezado a cargar ${ }^{147}$. Lo mismo se establecía, en cuanto al abono de la mitad del flete, en la Ordenanza de la Marina de 1681, en el fletamento "a cueillette", por quintales o toneladas, cuando el mercader retiraba las mercancías antes de que zarpase la nave ${ }^{148}$ y en el Código de Comercio de $1807^{149}$ o en el español de 1885, tanto si la descarga acontecía con carácter previo al inicio de la travesía ${ }^{150}$ como si el fletador rescindía de manera unilateral el contrato antes de cargar el buque ${ }^{151}$.

Una vez comenzado el viaje cualquiera de las partes podía decidir no continuar y volver al puerto de origen, aunque se hubiese pagado parte del precio, incumpliéndose, por tanto, el contrato. Según la compilación rodia, si tomaba la decisión el fletador perdía la cantidad abonada y si contravenía el patrón se le exigía devolver la mitad del flete doblado ${ }^{152}$. En las Ordenanzas de Trani de 1063,

147 LCM, caps. LXXXIII y LXXXIV, edición de PARELLADA, cit. (n. 26), pp. 35 y 36 y caps. XXXVIII [83] y XXXIX [84], edición de Pardessus, cit. (n. 26), II, pp. 82-83 y 83-85.

${ }_{148}$ Ordonnance touchant la marine du Mois d'Aồt 1681, lib. III, tít. 3º, art. 6. Exige Valin que tuviese motivos para retirar los bienes y no fuese un simple capricho (aunque la norma no dice nada al respecto). Descubre cierta contradicción entre esta disposición y la que imponía el abono del precio completo cuando no se cargaban todas las mercancías pactadas [VALIN, R. J., cit. (n. 29), I, p. 612]. Según Pardessus era una modificación introducida por vía consuetudinaria [Pardessus, J. M., cit. (n. 16), IV, p. 361, n. 6]. Cfr. Pothier, R. J., cit. (n. 29), pp. 76-80 y FERNÁNDEZ-GUERRA FERnÁNDEZ, R., cit. (n. 58), p. 128.

149 Code de commerce de 1807, art. 291. Sin distinguir tipo fletamentario, se imponía al fletador que desistía del viaje, antes de salir la nave sin haber cargado nada, el pago de la mitad del flete pactado (Code de commerce de 1807, art. 288).

150 Código de Comercio de 1885, art. 685.

151 Código de Comercio de 1885, art. 688.1. Otras causas por las que el fletador podía rescindir unilateralmente el contrato, estando obligado el fletante a indemnizar los perjuicios eran la inexactitud del certificado de arqueo en cuanto a la cabida del buque, el error en la designación del pabellón con que navega o no poner la nave a disposición del fletador en el plazo y forma convenidos (Código de Comercio de 1885, arts. 688.2 y 688.3).

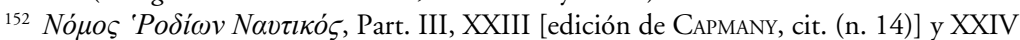
[ediciones de Pardessus y Ashburner, cits. (n. 14)]. Según Pardessus, este precepto estaría en contradicción con otros (caps. XX y XXIII de su edición) que parecen exigir al mercader que no cumplía el pago de todo el flete. A su entender, la razón podría estar en que la compilación recoge una serie de usos marítimos, con redacción defectuosa, que se han ido modificando con el tiempo. Otra explicación sería que en este cap. había un motivo justificado que no permitía seguir la travesía, cosa que no se indica, siendo la sanción menor que cuando se interrumpía por "mala voluntad". Una última posibilidad era que la norma partía de que el mercader había satisfecho ya la mitad del flete disponiendo que pagase el resto y no que perdiese lo abonado [PArdessus, Jean Marie, cit. (n. 14), I, p. 250, n. 1]. Pensamos que Pardessus no advierte que la otra regla no aludía a un viaje comenzado sino a que se hubiese empezado a cargar la nave. Para Ashburner, los capítulos donde se castigaba el incumplimiento con el precio total regulaban la situación de que el transportista pudiese perder la travesía por culpa del mercader, mientras que aquí no existía dicho riesgo y los posibles perjuicios quedaban cubiertos con el flete correspondiente al tiempo en el que el buque se había utilizado. Opinión similar sostiene de lo establecido 
el mercader que descargaba los géneros cuando el buque regresaba a puerto era castigado con el pago del precio tota ${ }^{153}$, porque renunciaba al contrato una vez empezada la travesía. Del mismo modo, si el desistimiento tenía lugar después de zarpar la nave se debían los fletes completos tanto en las Costums de Tortosa ${ }^{154}$, como en el $L C M^{155}$, en la Ordenanza de la Marina de $1681^{156}$, en el Código de Comercio francés de $1807^{157}$ o en el español de $1885^{158}$.

En cuanto al pasaje, al margen de la posible aplicación analógica de algunas de las reglas anteriores, según el $L C M$, el capitán no estaba obligado a devolver lo que había pagado el pasajero que decidía no realizar el viaje, se ausentaba sin licencia o no comparecía en el momento de zarpar, perdiendo las cantidades que había entregado, ya fuese una reserva de plaza o el flete completo. El patrón que recibía una señal del pasajero debía cumplir el contrato, excepto en caso de ausencia, pero aquel tenía que presentarse ante el capitán o el escribano tres días antes de la salida prevista. Ahora bien, dicho pasajero debía solicitar al patrón un plazo para embarcar y si era inferior al convenido y no podía partir, aquel tenía que devolverle la totalidad del flete e indemnizarle por los perjuicios ${ }^{159}$. Ante la laguna del Código de Comercio francés por lo que al pasaje se refiere, Pardessus considera que habría que atenerse a lo pactado por las partes. No obstante, si no había acuerdo se podían aplicar las normas fletamentarias, como la relativas al pago del precio íntegro si el pasajero abandonaba la nave antes de finalizar la travesía $^{160}$. Por su parte, el Código de Comercio español de 1885 señalaba que, si el viaje se suspendía, antes de comenzar, por culpa del transportista, el pasajero tenía derecho a la devolución del pasaje y a una indemnización de daños y perjuicios ${ }^{161}$; pero si se interrumpía, una vez iniciado, por hecho imputable exclusivamente al

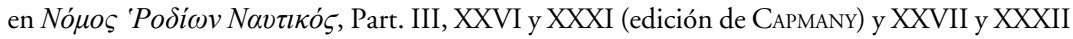
(edición de PARDESSUS y en la suya propia) [Ashburner, W., cit. (n. 14), pp. CXCIV y CCIV].

${ }^{153}$ Ordinamenta et consuetudo maris edita per consules civitatis Trani, V, edición de PARDESSUS, J. M, cit. (n. 95), V, p. 239.

154 Costums de Tortosa, IX, 27, 26, párrafo 1. Aquí también se debía a los marineros el sueldo completo.

155 LCM, cap. LXXXIV, edición de PARelLADA, cit. (n. 26), p. 36 y XXXIX [84], edición de PARDESSUS, cit. (n. 26), II, pp. 83-85. Si durante la travesía, la mayoría de los fletadores o aquellos con el mayor volumen de cargamento decidían desembarcar parte del mismo e interrumpir el viaje, el capitán podía obligarles a descargar el resto cobrando la totalidad de los fletes; pero si rebajaba el precio a los que desembarcaban la mayoría de las mercancías, tenía que hacer lo mismo con los demás [LCM, cap. CIV, edición de ParelladA, cit. (n. 26), p. 49 y LIX [104], edición de PARDESSUS, cit. (n. 26), II, p. 108].

156 Ordonnance touchant la marine du Mois d'Aô̂t 1681, lib. III, tít. 3º, art. 8.

${ }_{157}$ Code de commerce de 1807, art. 293.

${ }^{158}$ Código de Comercio de 1885, art. 684. Se obligaba al mercader que decidía descargar sus mercancías antes de llegar al puerto de destino a pagar el flete completo, además de los gastos, daños y perjuicios ocasionados.

159 LCM, caps. CXVI y CXXII, edición de Parellada, cit. (n. 26), pp. 55 y 57; CXV y CXXI, edición de CAPMANY, cit. (n. 26), pp. 188 y 193 y LXXI [116] y LXXVII [122], edición de Pardessus, cit. (n. 26), II, pp. 117-118 y 120-121.

${ }^{160}$ Pardessus, J. M., Cours, cit. (n. 34), III, pp. 244-245 y 247. Cfr. Bonniel, Y., cit. (n. 6), pp. 43-44.

${ }_{161}$ Código de Comercio de 1885, art. 697. 
capitán, el pasajero debía pagar en proporción a la distancia recorrida, aunque podía reclamar un resarcimiento de los perjuicios ${ }^{162}$. Ahora bien, si no llegaba "a bordo a la hora prefijada" o dejaba el buque sin permiso cuando se disponía a zarpar, el capitán podía emprender la travesía y "exigir el precio por entero"163. En la Ley de Navegación Marítima de 2014, si el pasajero no embarca en la fecha prevista se extingue el contrato y el porteador hace suyo el precio del pasaje, salvo que no sea voluntariamente sino que se deba a enfermedad o fallecimiento del pasajero o de algún familiar que le acompañe y se haya notificado sin demora o se haya podido sustituir al pasajero por otro ${ }^{164}$.

\section{Incumplimiento involuntario}

Nos ocupamos ahora de los supuestos en los que había un motivo justificado que imposibilitaba el viaje o en los que los géneros se perdían por causas no imputables a las partes (naufragio, echazón...), es decir, que el incumplimiento o la no ejecución del contrato era involuntaria. En el Constitutum usus de Pisa se mencionaban, entre dichas causas, la enfermedad del patrón, la captura por piratas, la detención o embargo por orden de la justicia y otras similares ${ }^{165}$, pudiéndose incluir las condiciones meteorológicas adversas. Según los Estatutos de Marsella, no había responsabilidad en estas hipótesis de fuerza mayor ${ }^{166}$ ya que impedían cumplir con el contrato dando lugar a la resolución de pleno derecho. Del mismo modo, las Costums de Tortosa permitían a cualquiera de las partes desistir del contrato sin penalización en los casos de fuerza mayor, estando el mercader y el pasajero exentos de pagar el flete ${ }^{167}$.

Más amplia es la regulación del $L C M$. Si el fletador desembarcaba las mercancías por algún impedimento habiendo abonado el flete, el patrón no estaba obligado a devolverlo, pero debía efectuar el transporte pactado si la situación cambiaba en un plazo de dos meses ${ }^{168}$. Cuando no había desembolsado nada y cesaba el impedimento tenía que cargar los géneros y en caso de negativa, satisfacer

${ }_{162}$ Código de Comercio de 1885, art. 698.1

163 Código de Comercio de 1885, art. 694. Si el contrato se rescindía, antes o después de iniciar la travesía, el capitán podía reclamar lo que hubiese "suministrado a los pasajeros" (Código de Comercio de 1885, art. 699). Es más, se debía la mitad del flete cuando el pasajero fallecía antes del comienzo del viaje, por parte de sus herederos, salvo que fuese sustituido por otro (Código de Comercio de 1885, art. 696).

164 Ley 14/2014, de 24 de julio, de Navegación Maritima, art. 297. a).

165 Constitutum usus, rúb. XIII, de naulo navium, edición de Pardessus, Jean Marie, cit. (n. 16), IV, p. 575.

166 Statuta civitatis Massiliae, lib. IV, cap. IX, edición de PArdessus, J. M., cit. (n. 16), IV, pp. 270-271. Cfr. Pardessus, J. M., Cours, cit. (n. 34), III, pp. 171 y 174-175.

167 Costums de Tortosa, IX, 27, 26, párrafo 3. Se trataba de los supuestos en los que la travesía no se realizaba por prohibición de la autoridad, por un bloqueo, interdicción del comercio o por temor a un ataque enemigo o de piratas que pudiera dañar la nave, la carga o las personas que iban a bordo. Tampoco el naviero tenía que pagar el salario a los marineros. El peligro debía ser "verdadero y no imaginario" [Oliver, Bienvenido, cit. (n. 23), III, pp. 290-291].

168 LCM, cap. LXXX, edición de Parellada, cit. (n. 26), p. 34 y cap. XXXV [80], edición de Pardessus, cit. (n. 26), II, pp. 80-81. 
el precio completo ${ }^{169}$. Cualquier mercader podía descargar los bienes sin pago alguno ante una amenaza de piratas, corsarios o enemigos, con independencia de que sus sospechas fuesen fundadas, siempre que hiciera lo mismo la mayoría, porque, de lo contrario, debía abonar el flete, salvo que llegase a otro acuerdo con el capitán ${ }^{170}$. Este devolvería las mercancías pudiendo el fletador volver a embarcarlas si desaparecía la causa de sus temores; pero si las vendía y cargaba otras adeudaba el mismo precio en proporción a las quintaladas para compensar al patrón los perjuicios ocasionados y los gastos de los alimentos y salarios de los marineros ${ }^{171}$. El mercader no debía flete si no podía cargar la nave por prohibición de la autoridad ya que se trataba de una causa que no le era imputable, aunque la conociera previamente, siempre que el capitán estuviese también al tanto y si no lo estaba, podía reclamar el precio y los gastos, previa prueba de que el fletador tenía noticia de dicha circunstancia antes de formalizar el contrato ${ }^{172}$. El patrón tenía que esperar el tiempo pactado y si ya no había impedimento, efectuar la carga sin aumentar los fletes, correspondiendo los gastos de la espera a ambas partes ${ }^{173}$. Un temporal, un ataque enemigo o cualquier otro accidente fortuito podía motivar que el buque zarpara antes de ser cargado; si el capitán reclamaba los fletes, debía volver al sitio pactado para embarcar los géneros una vez desaparecida la causa que le obligó a partir. Si se negaba y los mercaderes fletaban otra nave más cara, debía pagarles la diferencia y, además, estos no adeudaban fletes porque el patrón incumplía su obligación de transportar las mercancías por causa ajena a ellos ${ }^{174}$. Cuando el buque se tenía que cargar en un lugar distinto al de formalización del contrato y sobrevenía un impedimento, antes de que el capitán partiera hacia dicho lugar y los fletadores lo forzaban a acudir, no pudiendo entregar los géneros, debían hacer frente a los gastos y fletes ${ }^{175}$.

La Ordenanza de la Marina de 1681 permitía resolver el contrato de fletamento sin derecho a indemnización cuando se prohibía el comercio con las localidades de destino, antes de la salida de la nave, a causa de guerra, represalias o cualquier otro motivo, siendo a cuenta del mercader la carga y descarga de sus bienes ${ }^{176}$.

169 LCM, cap. CV, edición de Parellada, cit. (n. 26) p. 50 y LX [105], edición de ParDESSUS, cit. (n. 26), II, p. 109.

${ }^{170}$ LCM, caps. LXXXI y CIII, edición de Parellada, cit. (n. 26), pp. 34-35 y 49 y caps. XXXVI [81] y LVIII [103], edición de PARDESSUs, cit. (n. 26), II, pp. 81 y 108.

${ }^{171}$ LCM, cap. LXXXII, edición de Parellada, cit. (n. 26), p. 35 y cap. XXXVII [82], edición de PARDESSUS, cit. (n. 26), II, p. 81.

${ }^{172}$ LCM, cap. CXCII, edición de PARELladA, cit. (n. 26), pp. 83-85 y cap. CXLVII [192], edición de PARDESSUS, cit. (n. 26), II, pp. 161-163.

${ }^{173}$ LCM, cap. CCLXXXII, edición de PARELlada, cit. (n. 26), pp. 171-172 y CCXXXVII [282], edición de Pardessus, cit. (n. 26), II, pp. 317-320. Si el impedimento no desaparecía ninguna parte debía esperar más.

${ }^{174}$ LCM, cap. CCLXXXV, edición de Parellada, cit. (n. 26), pp. 177-178 y cap. CCXL [285], edición de PARDEssus, cit. (n. 26), II, pp. 328-329.

175 LCM, cap. CCLXVI, edición de Parellada, cit. (n. 26), pp. 153-155 y cap. CCXXI [266], edición de PARdessus, cit. (n. 26), II, pp. 285-287.

176 Ordonnance touchant la marine du Mois d'Aô̂t 1681, lib. III, tít. 1º, art. 7. Sin embargo, el contrato tendría plena vigencia si la referida prohibición no afectaba a los países de destino (Ordonnance touchant la marine du Mois d'Aồt 1681, lib. III, tít. 1º, art. 7, in fine). 
Lo mismo se establecía en el Código de Comercio francés de $1807^{177}$ y, en sentido similar, se pronunciaba el español de $1885^{178}$. Ahora bien, si una vez que el buque había zarpado, se imponía una prohibición del comercio en relación a los lugares en los que hacía escala, debiendo regresar con toda la carga, solo se pagaba el flete del viaje de ida, aunque el fletamento fuese de ida y vuelta ${ }^{179}$, manteniéndose este principio en el Código de Comercio francés de $1807^{180}$ y, con matices, en el español de $1885^{181}$ y en la Ley de Navegación Marítima de $2014^{182}$. Seguía vigente el contrato sin indemnización cuando solo había un cierre temporal de puertos o retención pasajera de la nave por orden de las autoridades, antes o después de la partida, sin que llegase a impedirse el comercio ${ }^{183}$. En estos supuestos, las partes tenían que esperar a que se resolviese la situación y cada una soportaba las consecuencias de este hecho, ya que no estaban obligadas a asumir los riesgos de eventos extraordinarios. Igual se disponía en el Código de Comercio de $1807^{184} \mathrm{y}$ en el español de $1885^{185}$. Por otra parte, si el buque se había fletado por meses, no se adeudaba flete hasta el desbloqueo del puerto o la liberación y si era por viaje,

Cfr. Pothier, Robert Joseph, cit. (n. 29), pp. 62 y 90-92. Si había una declaración de guerra posterior que incidía en los puertos de escala, el riesgo era a cuenta de la embarcación, de modo que el patrón no podía incrementar el flete alegando tal circunstancia [VALIN, René Josué, cit. (n. 29), I, p. 593].

177 Code de commerce de 1807, art. 276.

${ }^{178}$ Se declaraba rescindido el contrato y extinguidas todas las acciones cuando antes de partir la nave acontecía un supuesto de fuerza mayor que impedía su ejecución: inaccesibilidad al puerto de destino por guerra, bloqueo, peste o prohibición del comercio o de recibir las mercancías o detención indefinida por embargo del buque por orden del gobierno o por su incapacidad para navegar sin culpa del capitán (Código de Comercio de 1885, art. 690).

${ }_{179}$ Ordonnance touchant la marine du Mois d'Août 1681, lib. III, tít. $3^{\circ}$, art. 15. Ver POTHIER, Robert Joseph, cit. (n. 29), pp. 68-70. Si el viaje era solo de ida se adeudaba el flete del mismo, ya que la interrupción tenía su origen en una causa extraordinaria independiente de los riesgos marítimos [VAlin, René Josué, cit. (n. 29), I, pp. 622-623].

${ }^{180}$ Code de commerce de 1807, art. 299.

${ }^{181}$ Se adeuda el flete de ida si la nave debe volver al puerto de salida por riesgo de piratas, enemigos o circunstancias meteorológicas adversas o si tiene que arribar al lugar designado por el fletador por declaración de guerra, cierre de puertos o prohibición de comercio (Código de Comercio de 1885, arts. 688. 4 y 692).

182 Si durante la travesía sobrevienen "circunstancias fortuitas" que hacen "imposible, ilegal o prohibida su continuación" o "un conflicto armado" que someta al buque o a la carga a riesgos no previstos al contratar, el porteador puede desembarcar los géneros en el puerto que estime más conveniente, teniendo derecho al flete proporcional al trayecto realizado. Para su cálculo, se tienen en cuenta la distancia, "el coste, el tiempo y los riesgos de la parte recorrida en proporción al viaje total" (Ley 14/2014, de 24 de julio, de Navegación Marítima, art. 274).

183 Ordonnance touchant la marine du Mois d'Août 1681, lib. III, tít. 1º art. 8. Véase PARDESsus, Jean Marie, Cours, cit. (n. 34), III, p. 175 y PothiER, Robert Joseph, cit. (n. 29), pp. 92-93.

${ }^{184}$ Se hablaba de fuerza mayor que impedía temporalmente la partida de la nave o que acontecía durante el viaje (Code de commerce de 1807, art. 277).

185 Se mantenía el contrato de fletamento sin derecho a indemnización si el buque no podía zarpar por cierre pasajero del puerto de salida o cuando la declaración de guerra o bloqueo se producía durante la navegación. En este último caso, el capitán se dirigiría al puerto más cercano en espera de instrucciones del fletador, adeudándose el flete de ida si decidía desembarcar las mercancías. Si no recibía instrucciones, pasado un tiempo, a juicio del juez o tribunal, se 
el precio no se incrementaba ${ }^{186}$. En idéntico sentido se regulaba esta situación en el Código de Comercio de $1807^{187}$. Además, en estos casos, el mercader podía descargar mientras los géneros corriendo con los gastos, pero tenía que volver a cargarlos o indemnizar al patrón, si no lo hacía o incurría en demora, pagando la mitad del flete si se negaba de forma expresa o su totalidad, si no manifestaba su intención y la nave zarpaba ${ }^{188}$.

Todo lo anterior se podría aplicar al contrato de pasaje ${ }^{189}$. Según el Código de Comercio español de 1885, si, antes de comenzar, el viaje se suspendía por caso fortuito, fuerza mayor o cualquier motivo independiente del transportista, el pasajero solo tenía derecho a la devolución del pasaje ${ }^{190}$. Pero si se interrumpía una vez iniciado por las mismas causas, el pasajero debía el precio proporcional a la distancia recorrida, sin indemnización ${ }^{191}$. La reglas se mantienen en la Ley de Navegación Marítima de $2014^{192}$.

También se podía producir un incumplimiento involuntario del contrato cuando el buque tenía un daño que le impedía seguir con la navegación, por causa ajena al transportista, sin que se viese afectada la carga ni las personas que estaban a bordo. Aquí la legislación histórica solía dejar en manos del capitán la decisión entre reparar la nave y continuar con el transporte o trasladar las mercancías a otro buque convenido con el mercader; pero si no se podía restaurar o no se hacía a tiempo, debía proporcionar otro barco para llegar al puerto de destino, pudien-

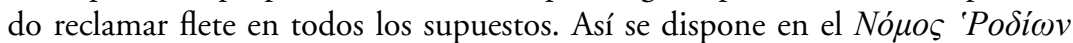

depositaban los géneros quedando afectos al pago del flete (Código de Comercio de 1885, arts. 691, 677 y 678).

186 Ordonnance touchant la marine du Mois d'Août 1681, lib. III, tít. 3º, art. 16. En estos casos, el salario y la alimentación de los marineros, mientras duraba la detención, se consideraba avería común. Ver Valin, R. J., cit. (n. 29), I, p. 593; Pardessus, J. M., cit. (n. 16), IV, p. 362, n. 7 y Cours, cit. (n. 34), III, p. 176 y Pothier, R. J., cit. (n. 29), pp. 81-83.

${ }_{187}$ Code de commerce de 1807, art. 300.

188 Ordonnance touchant la marine du Mois d'Aô̂t 1681, lib. III, tít. 1º, art. 9. La fuerza mayor suspendía el contrato que debía ejecutarse cuando fuese posible [PARDESSUS, J. M., cit. (n. 16), IV p. 359, n. 7 y Cours, cit. (n. 34), III, pp. 175-176]. Cfr. Pothier, R. J., cit. (n. 29), p. 93 y Valin, R. J., cit. (n. 29), I, p. 594. Véase Code de commerce de 1807, art. 278.

${ }^{189}$ Indica Bonniel que en el derecho francés, el pasajero podía exigir una exención o reducción del precio pactado si la nave no partía por causa de fuerza mayor (o imputable al armador) o si era detenida durante la travesía o esta se interrumpía por motivos similares [BonNIEL, Y., cit. (n. 6), pp. 43-46].

${ }^{190}$ Código de Comercio de 1885, art. 697.

${ }^{191}$ Código de Comercio de 1885, art. 698.1

${ }^{192}$ Ley 14/2014, de 24 de julio, de Navegación Marítima, art. 29. b) y e). Cualquier circunstancia bélica con riesgo para el pasajero o el buque, surgida antes o durante el viaje, permitía a ambas partes resolver el contrato sin indemnización [Ley 14/2014, de 24 de julio, de Navegación Maritima, art. 297. d)]. 


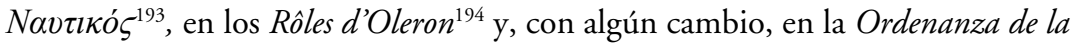
Marina de $1681^{195}$ o en el Código de Comercio de $1807^{196}$. Las Costums de Tortosa concedían, además, al naviero la opción de resolver el contrato entregando los géneros y exigiendo el flete por la parte del viaje realizada ${ }^{197}$. Una regulación inspirada en estos principios, con ciertas precisiones, es la que ofrece nuestro Código de Comercio de 1885, tanto en relación al pasaje ${ }^{198}$ como al fletamento ${ }^{199}$, y la Ley de Navegación Maritima de $2014^{200}$.

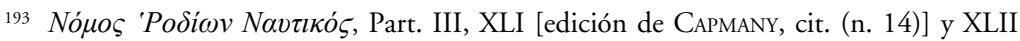
[ediciones de PARdessus y Ashburner, cits. (n. 14)]. Según Ashburner, la redacción del precepto induce a la duda de si los mercaderes pagaban todos los fletes o si el capitán abonaba el de la nave de sustitución, en cuyo caso, si este era superior estaría soportando el excedente, al pagar más de lo que había recibido. Esta última es la interpretación de Pardessus y la de Capmany, al menos cuando la reparación no era posible [AsHburner, W., cit. (n. 14), pp. XV y CCVIII-CCIX y PARdessus, J. M., cit. (n. 14), I, p. 326, n. 1].

${ }^{194}$ El maestre podía retener los géneros mientras el buque era reparado, debiendo, por tanto, los mercaderes esperar y pagar el flete, al igual que si no se podía reparar y se continuaba la travesía en otra nave (Rôles d'Oléron, IV).

195 El fletador debía esperar el arreglo o abonar el flete completo, pero si el daño no era subsanable ni se podía sustituir el buque se pagaba el precio proporcional al trayecto realizado (Ordonnance touchant la marine $d u$ Mois d'Août 1681, lib. III, tít. 3º, art. 11). Esto solo se aplicaba cuando la necesidad de reparación era por caso fortuito o fuerza mayor, ya que si era por culpa del patrón, recaía la carga de la prueba en el mercader y, en tal caso, aquel perdía el flete y debía indemnizar por los perjuicios (Ordonnance touchant la marine du Mois d'Aồt 1681, lib. III, tít. $3^{\circ}$, art. 12). La sustitución de la nave se dejaba a elección del capitán si quería cobrar el flete completo pero se permitía que los mercaderes se negasen [VALin, R. J., cit. (n. 29), I, pp. 617-619].

${ }_{196}$ Code de commerce de 1807, art. 296. El criterio es el mismo que el de la Ordenanza de 1681 cuando la reparación y la sustitución no eran viables. Además, el patrón perdía el flete y respondía de los daños e intereses si el fletador probaba que el buque cuando zarpó no estaba en condiciones de navegar (Code de commerce de 1807, art. 297).

197 El plazo para conseguir otra nave para terminar la travesía, trasladando la carga, era de ocho a quince días pudiendo exigirse, al llegar al destino, el total del flete, sin que la otra parte pudiera oponerse siempre que no hubiese una demora excesiva (Costums de Tortosa, IX, 27, 33). También se pagaba el flete completo cuando, por caso fortuito, el buque debía dirigirse al puerto más cercano para ser reparado y poder seguir el viaje, aunque los cargadores no quisieran continuar en el mismo (Costums de Tortosa, IX, 27, 34). Cfr. Oliver, B., cit. (n. 23), III, p. 293.

${ }^{198}$ Cuando la travesía se interrumpía por inhabilitación de la nave, el pasajero podía decidir esperar a que fuese reparada, sin aumento del precio, aunque corría a su cargo su alimentación (Código de Comercio de 1885, art. 698.1).

199 Si había que arribar a puerto para reparaciones urgentes, los fletadores podían optar por disponer de los géneros, pagando el flete de ida si la dilación no excedía de treinta días y el proporcional a la distancia recorrida si superaba dicho plazo (Código de Comercio de 1885, art. 698.5). Recordemos que se rescindía el contrato si el buque era incapaz de navegar sin culpa del capitán (Código de Comercio de 1885, art. 690). Pero este perdía el flete si los cargadores probaban que no estaba en condiciones de zarpar en el momento de recibir la carga (Código de Comercio de 1885, art. 676).

${ }^{200}$ Cuando una avería u otra circunstancia interrumpa el viaje, impidiendo la navegación, el porteador debe subsanar la situación, arribando a puerto y custodiando las mercancías. Pero si no es posible la subsanación o podría haber un retraso que afecte gravemente a la carga, tiene que proporcionar a su costa un transporte alternativo (salvo en el fletamento por tiempo), de lo contrario los géneros no devengan flete alguno, al margen de otras responsabilidades si la 
Lógicamente, tampoco se ejecutaba el contrato en los casos en los que las mercancías (o los efectos personales de los pasajeros) se perdían por naufragio o echazón ${ }^{201}$, lo cual repercutía también en el flete. Por razones de espacio no desarrollamos esta compleja cuestión, pero podemos afirmar que en la mayoría de los textos escritos se imponía el principio de que se abonase por completo (o la mitad) en relación a los bienes salvados, no pudiéndose reclamar por los perdidos $^{202}$, aunque en otros, se podía exigir tanto por los salvados como por los perdidos, a veces a elección del patrón, determinando así su contribución a la indemnización ${ }^{203}$.

\section{CONCLUSIONES}

Aunque las principales conclusiones a las que hemos llegado a través de nuestra investigación se han ido insinuando y concretando al hilo de la exposición de los distintos apartados, creemos necesario repasar las mismas para cerrar nuestro trabajo. De hecho, el propio planteamiento y desarrollo constituyen por sí mismos conclusiones alcanzadas a partir de algunos de los resultados obtenidos en el seno del proyecto de investigación más amplio en el que se ubica el estudio y que ya se adelantaba desde el principio.

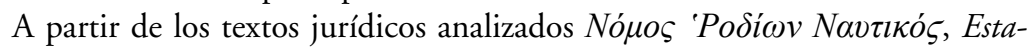
tutos de Marsella de 1253 a 1255, Rôles d'Oléron, Costums de Tortosa, Llibre del Consolat de Mar, Ordenanza de la Marina de 1681, Código de Comercio frances de 1807 o Código de Comercio español de 1885, entre otros) y que, como decíamos, consideramos representativos en la historia del Derecho marítimo, hemos conseguido delimitar algunos lugares comunes en relación a la regulación de la obligación de pago del flete en el contrato de fletamento y de pasaje marítimo,

causa de la innavegabilidad le fuera imputable (Ley 14/2014, de 24 de julio, de Navegación Maritima, art. 224).

${ }^{201}$ Habría otras hipótesis de pérdida de los géneros con repercusión en el flete como, por ejemplo, que fuesen apresados durante el viaje [ $L C M$, cap. CCXXXII, edición de PARELLADA, cit. (n. 26), pp. 113-115 y CLXXXVII (232), edición de PARDESSus, cit. (n. 26), II, pp. 212-215] o que el buque fuese capturado [ $L C M$, cap. CCLXXVI, edición de PARELLADA, cit. (n. 26), pp. 164-165 y CCXXXI (276), edición de PARDESSUs, cit. (n. 26), II, pp. 303-307] y rescatado (Ordonnance touchant la marine du Mois d'Août 1681, lib. III, tít. 3º, arts. 19 y 20; Code de commerce de 1807, arts. 303 y 304).

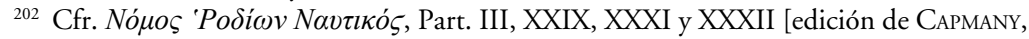
cit. (n. 14)] y XXX, XXXII y XXXIII [ediciones de Pardessus y Ashburner, cits. (n. 14)]; Statuti anconitati del mare, rúb. XXV [edición de Pardessus, J. M., cit. (n. 95), V, p. 139]; Rôles d'Oléron, IV; Costums de Tortosa, IX, 27, 31; Ordonnance touchant la marine du Mois d'Août 1681, lib. III, tít. 30, arts. 18, 21 y 22; Code de commerce de 1807, arts. 302 y 303; Código de Comercio de 1885, arts. 660, 661, 662 y 663 y Ley 14/2014, de 24 de julio, de Navegación Maritima, art. 234. 1.

${ }^{203}$ Capitols del Rei en Pere, XXX; Rôles d'Oléron, XXXI; LCM, caps. XCVIII, CXCVI y CCLXXXIV, edición de ParelLadA, cit. (n. 26), II, pp. 46-47, 87-88 y 175-177 y caps. LIII [98], CLI [196], CCXXXIX [284], edición de PARDEssus, cit. (n. 26), II, pp. 102-104, 168-170 y 323-327. Véase también Ordonnance touchant la marine du Mois d'Aồt 1681, lib. III, tít. 3º, art. 13 y lib. III, tít. 8º, art. 7 y Code de commerce de 1807, arts. 301 y 417. 
que, sin duda, están también presentes en otros muchos aspectos contractuales. Se trata de una muestra de principios básicos que, con algunos matices, se han ido manteniendo en el tiempo, llegando más allá del derecho codificado hasta las normas más recientes sobre la materia como la Ley 14/2014, de 24 de julio, de Navegación Marítima vigente en España. Esto nos lleva a concluir que podrían servir de base para construir un derecho común europeo en materia de contratos marítimos, que, por otra parte, no sería una novedad en la historia.

Así, el pago del precio en el contrato de pasaje marítimo y del flete en el contrato de fletamento constituye la obligación principal del pasajero/mercader que debía constar en el contrato, siendo un principio elemental y común en el derecho histórico la primacía de la autonomía de la voluntad de las partes, reflejada en el correspondiente documento contractual, para su determinación, de modo que se acudía a la ley cuando no había nada acordado; sin embargo, algunos textos no recogían nada al respecto, decidiendo las autoridades judiciales.

A pesar de que las reglas no son del todo uniformes, el devengo del flete y la forma de pago, cuando no existía estipulación, se hacía depender del tipo fletamentario, pudiéndose admitir la aplicación analógica al contrato de pasaje de las disposiciones relativas al transporte de mercancías.

La opción de abonar el precio abandonando la totalidad de los géneros cargados, independientemente de cuál fuese su valor, como principio, se admitía en la práctica totalidad de los textos consultados, pero no se podía obligar al capitán a recibir en tal concepto los bienes en mal estado, ni los que habían perdido parte de su valor.

Asimismo, la mayoría de las leyes históricas reconocían el derecho del transportista a retener los bienes cargados en el buque como garantía del flete y de otras cantidades adeudadas, aunque hay cuerpos legales que optaban por el depósito y venta judicial de lo necesario para el cobro del precio y otros, por una combinación de ambos derechos.

Una regla general era que solo se podía exigir el flete cuando el contrato se cumplía y los géneros o los pasajeros llegaban en condiciones óptimas al puerto de destino acordado. Esto implica que el incumplimiento contractual o la imposibilidad de ejecutar el contrato tenía lógicas repercusiones en la obligación de pago, lo que no ha pasado desapercibido para el derecho histórico que se ocupaba de reglamentar las consecuencias de dichas infracciones cuando las partes no las habían convenido. Las normas castigaban estos supuestos con diferentes sanciones entre las que se encontraban las económicas dirigidas a compensar a la parte perjudicada por el incumplimiento, como principio incuestionable (aunque su concreción y cuantía difería en las distintas regulaciones) y que podían consistir en una indemnización o en la exención, reducción o devolución del precio, si ya se había pagado.

Hemos descubierto en las leyes analizadas algunas obligaciones cuya infracción repercutía directamente en el flete, manteniéndose las directrices en el tiempo. Así, en relación a la obligación de embarcar en las condiciones pactadas, el fletador que cargaba menos mercancías de las estipuladas en el contrato debía abonar también el precio de lo que faltaba, lo que es una constante en la legislación histórica, con 
alguna que otra excepción, como que se pudiera completar la capacidad de la nave con otros géneros. Si, por el contrario, embarcaba más bienes tenía que pagar el exceso, aunque había distintos criterios para fijar el importe. El fundamento de esta regla se encuentra en la obligación de declarar todo lo que se introducía en el buque que debía contar con el consentimiento del patrón. Por otra parte, el incumplimiento de la obligación de embarcar o cargar en el periodo señalado, sin provocar demoras, también tenía consecuencias en el flete que dependían de quién ocasionaba el retraso y de las posibles causas, pudiendo incrementarse, reclamarse por completo o exigirse su devolución.

El contrato de pasaje marítimo o el de fletamento podían ver interrumpida, modificada o imposibilitada su ejecución por voluntad de cualquiera de las partes contractuales o por circunstancias ajenas a las mismas, lo que nos ha permitido diferenciar un incumplimiento voluntario y otro involuntario. En la primera hipótesis, el principio que imperaba en el derecho histórico era acudir a lo recogido en el contrato y si nada se había pactado, se distinguía según si el desistimiento se producía antes o después de comenzar la carga o de empezar el viaje, consistiendo la sanción, en la mayoría de las ocasiones, en el pago de la mitad o de la totalidad del flete o de una indemnización, según el caso y el alcance de la infracción. Respecto al pasaje, la pauta general era que el pasajero que decidía no realizar la travesía debía abonar el precio íntegro al igual que si abandonaba el buque antes de que terminase la aventura marítima, pero si el hecho era imputable al transportista, el pasajero podía exigir la devolución del pasaje o pagar solo la parte proporcional a la distancia recorrida si el viaje ya se había iniciado.

Cuando el incumplimiento o la no ejecución del contrato eran involuntarios (captura por piratas, detención o embargo por orden de la justicia, prohibición del comercio o cualquier supuesto de fuerza mayor) el principio básico, al margen de los matices o de la regulación más o menos amplia de las diferentes normas, era que las partes podían desistir del contrato sin derecho a indemnización y el mercader o el pasajero no tenían que pagar el precio. Pero si el impedimento acontecía una vez que la nave había zarpado, debiendo regresar, se abonaba el flete de ida (aunque el fletamento fuese de ida y vuelta) o el precio proporcional al trayecto realizado en el caso del pasaje. Si el incumplimiento involuntario era a consecuencia de un daño en el buque que no le permitía continuar con la navegación, por causa ajena al transportista, la legislación histórica dejaba que el patrón optase entre reparar la nave y continuar el viaje o trasladar los géneros a otro buque; y si no era posible la restauración, debía conseguir otro barco para llegar al destino, pudiendo reclamar el flete en todos los supuestos. La pérdida de las mercancías por naufragio o echazón también impedía ejecutar el contrato y repercutía en el flete, siguiéndose en la mayoría de los textos el principio de que se pagase en su totalidad (o la mitad) en relación a los bienes salvados, sin que se pudiera exigir por los perdidos.

Consideramos, por tanto, factible un cuerpo legislativo único a nivel europeo en materia de contratos marítimos con base en los principios históricos, pero no intuimos disponibilidad ni voluntad por parte de los diferentes Estados europeos para configurar ese derecho común, sino que la opción es legislar a nivel nacional, 
como se demuestra con las últimas leyes promulgadas en diferentes países, siendo, a nuestro entender, motivos políticos más que jurídicos los que constituyen el principal obstáculo para el éxito de nuestra propuesta.

\section{BiBLIOGRAFÍA}

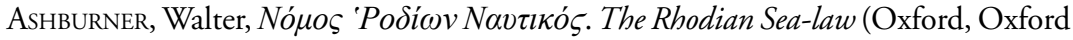
University Press, 1909; Aalen, 1976; Union, Nueva Jersey, Lawbook Exchange, 2001).

Bonniel, Y., Le contrat de passage (thèse pour le doctorat, Université d'Aix-Marseille-Faculté de Droit d'Aix, Aix-en-Provence, Imprimerie Universitaire E. Fourcine, 1936).

Boulay-Paty, P. S., Cours de droit commercial maritime, d'après les principes et suivant l'ordre du Code de commerce (Bruxelles, Société belge de librairie, etc. Hauman \& Comp., 1838), I.

Bühler, G., The Laws of Manu: The Sacred Books of the East Part Twenty-Five (edición de Müller, F. M., Oxford, Oxford University Press, 1885; reimpresión, Kessinger Publishing, 2004).

Campuzano Díaz, Beatriz, ¿Hacia un Derecho contractual europeo?, en Anuario de Derecho europeo 2 (2002), pp. 43-65.

Campuzano Díaz, Beatriz, El plan de acción para un Derecho contractual europeo más coherente, en Anuario Mexicano de Derecho Internacional 4 (2004), pp. 289-309.

Code de commerce, précédé des motifs. Présentés au Corps Législatif par M. Regnaud de Saint-Jean-d'Angely (Toulouse, Chez V. ${ }^{\mathrm{ve}}$ Douladoure, 1807).

Colon i Domènech, Germà y Garcia i SAnz, Arcadi, Llibre del Consolat de Mar (Barcelona, Fundació Salvador Vives Casajuana y Fundació Noguera, 1981-1987), 4 volúmenes, (reedición, Fundació Noguera, 2001), 1 volumen.

Crémieux, A., Le VI Ime livre des statuts de Marseille (Aix-en-Provence, F. Chauvet, 1917). de Capmany y de Montpalau, Antonio, Apéndice a las Costumbres Maritimas del Libro del Consulado (Madrid, Imprenta de Sancha, 1791).

de Capmany y de Montpalau, Antonio, Código de las Costumbres maritimas de Barcelona, hasta aqui vulgarmente llamado Libro del Consulado. Nuevamente traducido al castellano con el texto lemosin restituido a su original integridad y pureza; e ilustrado con varios apéndices, glosarios, y observaciones históricas (Madrid, Imprenta de Don Antonio de Sancha, 1791).

DE Fresquet, Raimond Frédéric, Étude sur les statuts de Marseille au XIII siècle (Aix-Marseille, Makaire, 1865).

FariÑA, Francisco, Derecho y Legislación maritimos (Madrid, Luis Pamies, 1951).

Fernández-Guerra Fernández, Ramón, El fletamento en las Ordenanzas del Consulado de Bilbao de 1737, en AHDE., 62 (1992), pp. 117-157.

GARCÍA CARACUEL, Manuel, La alteración sobrevenida de las circunstancias contractuales (Madrid, Dykinson, 2014).

Garrigues, Joaquín, Curso de Derecho mercantil (Madrid, S. Aguirre, 1940), II, 2.

JONES, William, Institutes of Hindu Law: or, the Ordinances of Menu, according to the gloss of Culluica; comprising the Indian system of duties, religious and civil (Calcutta, printed by order of the government, London, reprinted for J. Sewell, Cornhill \& J. Debrett, Piccadilly, 1796). 
KRIEGer, K-F., Ursprung und Wurzeln der Rôles d'Oléron (Köln, Wien, Böhlau Verlag, 1970).

Lois de Manou, comprenant les institutions religieuses et civiles des Indiens (traduites du sanscrit et accompagnées de notes par LoIseleur DeslongChamps, A., Paris, Imp. de Crapelet, 1833).

Lyon-Caen, Charles y Renault, Louis, Traité de droit commercial (Paris, F. Pichon et Durand-Auzias, 1906-1916), 8 volúmenes.

Massip i Fonollosa, Jesús, Costums de Tortosa (col-laboració de Duarte, C. y Massip, À. y "pròleg" de FonT i Rius, Josep M., Barcelona, Fundació Noguera, 1996).

Mayssoni, François, Le Consulat, contenant les Loix, Statuts, \& Coustumes touchant les Contracts, marchandises, \& negociation Maritime. Ensemble de la Navigation, tant entre Marchands, que Patrons de Navires, \& autres Mariniers (Aix-en Provence, Estienne David, 1635).

MÉNAGER, L-R., Naulum et Receptum rem salvam fore. Contribution à l'étude de la responsabilité contractuelle dans les transports maritimes, en droit romain", en RHDFE., 38 (1960), pp. 177-213; 385-411.

Oliver, Bienvenido, Historia del Derecho en Cataluña, Mallorca y Valencia. Código de las Costumbres de Tortosa (Madrid, Imprenta de Miguel Ginesta, 1879 y 1881), III y IV.

Olmedo Peralta, Eugenio, Régimen jurídico del transporte maritimo de pasajeros. Contratos de pasaje y crucero ("Prólogo" de Peinado Gracia, Juan Ignacio, MadridBarcelona-Buenos Aires-São Paolo, Marcial Pons, 2014).

Ordonnance de la marine, Du mois d'août 1681, Commentée \& Conférée avec les anciennes Ordonnances, le Droit Romain \& les nouveaux Réglemens (Paris, C. Osmont, 1714).

Parellada, J. R., Libro del Consulado del Mar (Madrid, Ministerio de Asuntos Exteriores, 1955).

Pardessus, Jean Marie, Collection de lois maritimes antérieures au XVIII siècle (Paris, L'Imprimerie Royale, 1828-1848; reedición anastática, Torino, 1968) 6 volúmenes.

Pardessus, Jean Marie, Cours de droit commerciaß (Paris, Chez Nève, Libraire de la Cour de Cassation, 1825), III.

Pérez Velázquez, Juan Pablo, El proceso de modernización del Derecho Contractual Europeo (Madrid, Dykinson, 2013).

Pernoud, Régine, Le IV $V^{\text {me }}$ Livre des statuts de Marseille (thèse complémentaire pour le Doctorat présentée à la Faculté des Lettres de l'Université de Paris, Marseille, A. GED, 1935).

Pothier, Robert Joseph, Supplément au Traité du Contrat de Louage, ou Traité des Contrats de Louage Maritimes (Paris, Chez les Frères Debure; Orléans, Chez la Veuve Rouzeau-Montaut, 1765).

Serna Vallejo, Margarita, Las previsiones penales y procesales maritimas de los Capitols del Rei en Pere de 1340 incluidos en el LCM, en Mundos Medievales: espacios sociedades y poder. Homenaje al profesor José Ángel García de Cortázar y Ruiz de Aguirre (Santander, Editorial de la Universidad de Cantabria, 2012), II, pp. 1901-1913.

Strehly, Georges, Mânava Dharma Çâstra. Les Lois de Manou (Paris, Ernest Leroux, 1893).

Tetley, William, Maritime Law as a Mixed Legal System (with Particular Reference to the Distinctive Nature of American Maritime Law, Which Benefits from Both Its Civil and Common Law Heritages, en Tulane Maritime Law Journal 23 (1999) 2, pp. 317-350.

Valin, René Josué, Nouveau Commentaire sur l'Ordonnance de la marine, Du Mois 
d'Août 1681. Où se trouve la Conférence des anciennes Ordonnances, des Us \& Coutumes de la Mer, tant du Royaume que des Pays étrangers, \& des nouveaux Réglemens concernans la Navigation \& le Commerce maritime. Avec des explications prises de l'esprit du texte, de l'Usage, des Décisions des Tribunaux \& des meilleurs Auteurs qui ont écrit sur la Jurisprudence nautique. Et des Notes historiques \& critiques, tirées la plupart de divers Recueils de Manuscrits conservés dans les dépôts publics (La Rochelle, Chez Jérôme Legier et Pierre. Mesnier, 1760), 2 volúmenes.

Zambrana Moral, Patricia, Historia del contrato de pasaje maritimo. Derecho medieval e hipótesis de la aplicación analógica de la normativa fletamentaria. Unificación del Derecho europeo (Saarbrücken, OmniScriptum GmbH \& Co. KG, 2013).

Zambrana Moral, Patricia, El transporte en la Ordenanza de la Marina francesa de 1681 (Cizur Menor, Aranzadi-Thomson Reuters, 2015). 